\title{
IMPACTO DOS CATALISADORES AUTOMOTIVOS NO CONTROLE DA QUALIDADE DO AR
}

\author{
Maria do Carmo Rangel* \\ Instituto de Química, Universidade Federal da Bahia, Campus Universitário de Ondina, 40170-290 Salvador - BA \\ Marly Fernandes Araújo Carvalho \\ Departamento Ciências Exatas e da Terra, Universidade do Estado da Bahia, Estrada das Barreiras, s/n, 41195-001 Salvador - BA
}

Recebido em 4/4/02; aceito em 17/6/02

\begin{abstract}
IMPACT OF AUTOMOTIVE CATALYSTS IN THE CONTROL OF AIR QUALITY. Advanced industrialized nations have experienced severe pollution problems over the past forty years, caused mainly by carbon monoxide, hydrocarbons and nitrogen oxide emissions from automobiles. Catalyst technology has played a major part in minimizing these emissions as required by even more restrictive laws. The catalyst has been optimized over the years to meet the requirements of high activity and long life. The oxidation of hydrocarbon and carbon monoxide are in advanced development stage while that of $\mathrm{NO}_{\mathrm{x}}$ catalysts is far less advanced. In the future, catalyst technology is expected to contribute to overcome the challenges to get a cleaner air.
\end{abstract}

Keywords: automotive catalysts; pollution; air quality.

\section{CONSIDERAÇÕES GERAIS}

Devido ao rápido movimento de seu meio fluido, a atmosfera tornou-se um dos mais convenientes lugares para o depósito de materiais indesejáveis, causando inúmeros problemas ambientais. Entre os principais, nos dias atuais, estão o aquecimento da Terra, a chuva ácida e o efeito estufa. Este último é causado por gases quimicamente estáveis e inertes o suficiente para se acumularem na atmosfera, tais como o dióxido de carbono, o metano, os óxidos de nitrogênio e os compostos fluorcarbonados clorados.

Um dos agentes que mais contribui para a poluição do ar é o automóvel. Em áreas urbanas, isso é demonstrado dramaticamente pela fumaça fotoquímica, resultante da interação entre óxidos de nitrogênio, hidrocarbonetos e luz solar, para formar produtos de oxidação, que causam irritação aos olhos, ao aparelho respiratório e danos às plantas ${ }^{1}$. Como os automóveis emitem esses compostos, além de monóxido de carbono, de dióxido de enxofre e de compostos aromáticos, eles contribuem diretamente para a fumaça fotoquímica e outras formas de poluição ${ }^{2}$.

O tipo e a composição do combustível usado nos automóveis influenciam, de modo significativo, nas diferentes formas de contaminação às quais o meio ambiente está sujeito. Os carros movidos a álcool, por exemplo, produzem altas emissões de aldeídos (principalmente formaldeído e acetaldeído) em relação àqueles movidos à gasolina. Os veículos movidos por misturas $20 \%$ etanol-gasolina (v/ v) emitem mais aldeídos totais e óxidos de nitrogênio do que a gasolina. São também elevadas as emissões de álcool não-carburado, principalmente com a ignição a frio ${ }^{3}$.

Os aldeídos e outros compostos carbonílicos, diretamente emitidos na atmosfera, participam como precursores de reações fotoquímicas, produzindo ácido nítrico e nitrato de peroxiacetila (PAN), entre outros ${ }^{4}$. Esses compostos são, em geral, fitotóxicos ou irritantes para os olhos ou vias respiratórias, como é o caso do PAN, do ozônio e do peróxido de hidrogênio ${ }^{5}$.

A combustão catalítica constitui a alternativa mais conveniente para eliminar compostos orgânicos, em baixas concentrações, em fase vapor. As principais vantagens desse processo, comparado com

*e-mail: mcarmov@ufba.br outras formas de descontaminação, são a alta eficiência em baixas concentrações de poluentes, pouco consumo de energia, uso de unidade de depuração de pequeno porte e baixa produção de poluentes secundários, principalmente óxidos de nitrogênio ${ }^{6}$. Ao lado dessas vantagens, a conscientização dos problemas causados pela poluição do ar e a diminuição das reservas de combustíveis fósseis resultaram num maior interesse por processos de combustão, que pudessem reduzir os níveis de emissão de poluentes e, ao mesmo tempo, aumentar a eficiência do próprio processo ${ }^{7}$.

Os esforços para empregar conversores catalíticos, no controle das emissões automotivas, datam da década de cinquenta. A maioria desses trabalhos foi direcionada para o mercado da Califórnia e focalizava os tipos de automóveis que possuíam os níveis mais elevados de emissões. Todavia, os conversores não foram comercializados, pois se observou que era mais econômico e conveniente modificar a carburação e a ignição e instalar componentes que reduzissem as emissões do motor ${ }^{8}$.

No final da década de sessenta, os padrões de exigência da qualidade do ar tornaram-se mais restritivos e tornou-se óbvio que as modificações no motor não seriam suficientes para atingir esses padrões. Seria necessário um sistema auxiliar e os conversores catalíticos tornaram-se os principais candidatos. Dessa forma, observou-se um grande esforço cooperativo entre fabricantes de catalisadores, de automóveis e de indústrias petrolíferas, que resultou em veículos de baixa emissão dotados de conversores catalíticos. Estes tinham a finalidade de eliminar os poluentes que a combustão do motor produzia ou não conseguia eliminar através das condições de operação otimizadas. Os primeiros sistemas eram constituídos por dois conversores ou um único possuindo dois leitos catalíticos; o primeiro catalisava a redução de óxidos de nitrogênio para nitrogênio, enquanto o segundo oxidava monóxido de carbono e hidrocarbonetos não-carburados a dióxido de carbono e água. Em 1970, foram propostos conversores que catalisavam ambas as reações simultaneamente, mas esses sistemas eram de uso limitado, devido à sua estreita faixa de valores da razão ar/combustível exigida para a carburação ${ }^{8}$.

No desenvolvimento desses catalisadores, buscava-se um sistema capaz de promover altas conversões de monóxido de carbono, óxidos de nitrogênio e hidrocarbonetos. Estes últimos estão presentes nos gases de exaustão como olefinas, parafinas e compostos aro- 
máticos com um a oito átomos de carbono. A Tabela 1 mostra os principais hidrocarbonetos encontrados nos gases de exaustão9. Outros constituintes comuns são o hidrogênio, cuja concentração está em torno de $1 / 3$ do teor de monóxido de carbono, vapor d'água e dióxido de carbono que ocorrem na faixa de $10 \%$ em volume. As emissões de dióxido de enxofre estão próximas a valores de 20 ppm, cuidando-se para que o nível de compostos sulfurados no combustível não exceda $0,03 \%$. O uso de combustíveis alternativos como etanol e metanol leva a um aumento na emissão de aldeídos 9 . A quantidade de poluentes varia de acordo com as condições operacionais do motor, mas é predominantemente influenciada pela razão ar/combustível no cilindro de combustão. A Figura 1 mostra as emissões de um motor a gasolina em função dessa razão ${ }^{10}$.

Quando o motor está operando com misturas deficientes em oxigênio, em relação à quantidade estequiométrica, as emissões de monóxido de carbono e hidrocarbonetos são mais elevadas, enquanto as de óxidos de nitrogênio são mais baixas, devido à queima incompleta da gasolina; o nível de óxidos de nitrogênio é reduzido porque a temperatura adiabática de chama é diminuída. Por outro lado, com misturas ricas em oxigênio a combustão é completa e as quantidades de monóxido de carbono e hidrocarbonetos são mais baixas; neste caso, a emissão de óxidos de nitrogênio é aumentada, uma vez que a temperatura de operação é mais baixa ${ }^{11,12}$. Quando o motor opera com a razão estequiométrica, a produção de óxidos de nitrogênio é máxima, porque a temperatura é aumentada.

As reações catalíticas mais importantes que ocorrem no sistema de exaustão são a oxidação do monóxido de carbono e hidrocarbonetos para formar dióxido de carbono e água, mostradas pelas equações (1) a (3) e a redução dos óxidos de nitrogênio, representadas pelas equações (4) a (6), a nitrogênio. Os produtos desejados (dióxido de carbono, água e nitrogênio) são termodinamicamente favorecidos nas temperaturas típicas de exaustão (770K). Entretanto, a conversão global é determinada não apenas pela atividade dos catalisadores para promover essas reações, mas também pela disponibilidade dos agentes redutores e oxidantes. Outras reações, tais como aquelas mostradas pelas equações (7) a (9), também podem ocorrer e, possivelmente, as representadas pelas equações (10) a (13) ${ }^{9}$.

$\mathrm{CO}+1 / 2 \mathrm{O}_{2} \longrightarrow \mathrm{CO}_{2}$

Hidrocarbonetos $+\mathrm{O}_{2} \longrightarrow \mathrm{H}_{2} \mathrm{O}+\mathrm{CO}_{2}$

$\mathrm{CO}+\mathrm{H}_{2} \mathrm{O} \longrightarrow \mathrm{CO}_{2}+\mathrm{H}_{2}$

$\mathrm{NO}(\mathrm{ou} \mathrm{NO})+\mathrm{CO} \longrightarrow 1 / 2 \mathrm{~N}_{2}+\mathrm{CO}_{2}$
$\mathrm{NO}+\mathrm{H}_{2} \longrightarrow 1 / 2 \mathrm{~N}_{2}+\mathrm{H}_{2} \mathrm{O}$

Hidrocarbonetos $+\mathrm{NO} \longrightarrow \mathrm{N}_{2}+\mathrm{H}_{2} \mathrm{O}+\mathrm{CO}_{2}$

$\mathrm{NO}+5 / 2 \mathrm{H}_{2} \longrightarrow \mathrm{NH}_{3}+\mathrm{H}_{2} \mathrm{O}$

$\mathrm{H}_{2}+1 / 2 \mathrm{O}_{2} \longrightarrow \mathrm{H}_{2} \mathrm{O}$

Hidrocarbonetos $+\mathrm{H}_{2} \mathrm{O} \longrightarrow \mathrm{CO}+\mathrm{CO}_{2}+\mathrm{H}_{2}$

$3 \mathrm{NO}+2 \mathrm{NH}_{3} \longrightarrow 5 / 2 \mathrm{~N}_{2}+3 \mathrm{H}_{2} \mathrm{O}$

$2 \mathrm{NO}+\mathrm{H}_{2} \longrightarrow \mathrm{N}_{2} \mathrm{O}+\mathrm{H}_{2} \mathrm{O}$

$2 \mathrm{~N}_{2} \mathrm{O} \longrightarrow 2 \mathrm{~N}_{2}+\mathrm{O}_{2}$

$2 \mathrm{NH}_{3} \longrightarrow \mathrm{N}_{2}+3 \mathrm{H}_{2}$

As equações (1) a (13) ilustram a necessidade de se considerar, em laboratório, as reações de oxidação e de redução, ocorrendo simultaneamente, assim como a ocorrência das reações secundárias, avaliando-se a influência de cada um dos componentes sobre a reação estudada. Dessa forma, há uma tendência dos trabalhos mais recentes em focalizar misturas gasosas, com composições próximas àquelas dos sistemas de exaustão. Todavia, historicamente, os traba-

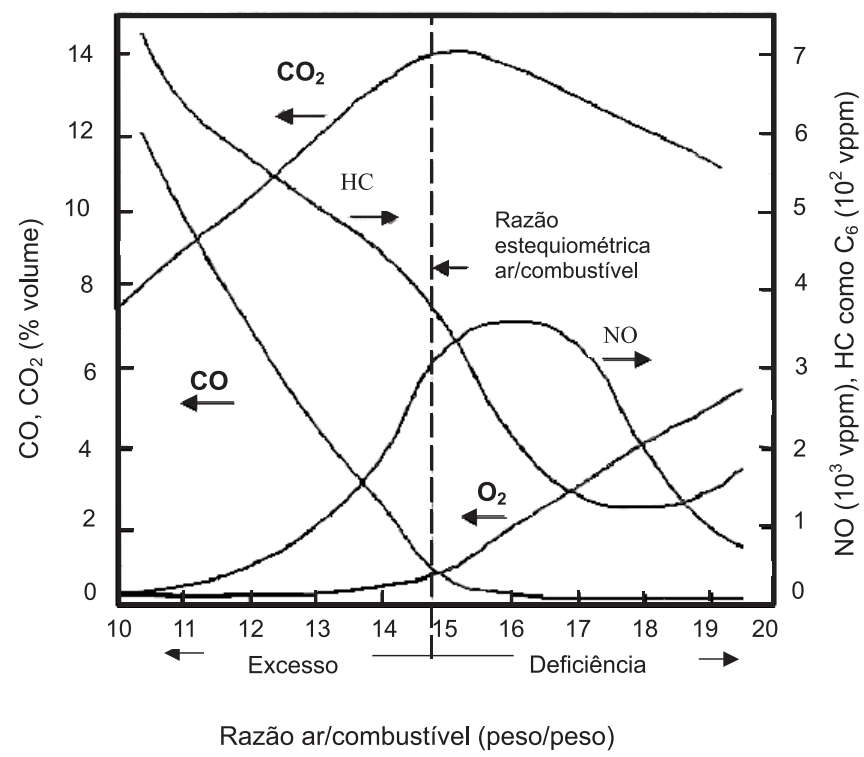

Figura 1. Emissões de um motor à gasolina em função da razão ar/ combustível ${ }^{10}$

Tabela 1. Hidrocarbonetos tipicamente encontrados nos gases de exaustão de automóveis (adaptado da ref. 9)

\begin{tabular}{|c|c|c|c|c|c|}
\hline \multicolumn{2}{|c|}{$\begin{array}{l}\text { Hidrocarbonetos não reativos } \\
\text { (em relação aos outros } \\
\text { componentes) }(\%)\end{array}$} & \multicolumn{2}{|c|}{$\begin{array}{l}\text { Hidrocarbonetos reativos } \\
\text { (em relação aos outros } \\
\text { componentes) }(\%)\end{array}$} & \multicolumn{2}{|l|}{$\begin{array}{l}\text { Classes de } \\
\text { hidrocarbonetos }(\%)\end{array}$} \\
\hline Acetileno & 0,3 & Etileno & 7,8 & Parafinas totais & 74,3 \\
\hline Metano & 28,0 & Tolueno & 7,7 & Olefinas totais & 9,9 \\
\hline Benzeno & 1,6 & Xilenos & 2,0 & Acetileno & 0,3 \\
\hline Etano & 4,5 & Propileno & 1,5 & Compostos aromáticos & 15,5 \\
\hline Propano & 0,3 & Trimetilpentanos & 15,6 & - & - \\
\hline - & - & n-Butano & 7,2 & - & - \\
\hline- & - & i-Pentano & 5,9 & - & - \\
\hline- & - & Butenos & 0,4 & - & - \\
\hline- & - & Metilpentanos & 1,5 & - & - \\
\hline- & - & n-Pentano & 0,8 & - & - \\
\hline- & - & Etilbenzeno & 0,6 & - & - \\
\hline- & - & i-Butano & 0,3 & - & - \\
\hline- & - & Outros & 14,0 & - & - \\
\hline Total & 34,7 & Total & 65,3 & - & - \\
\hline
\end{tabular}


lhos abordavam isoladamente a oxidação de monóxido de carbono e de compostos orgânicos voláteis ou a redução de óxidos de nitrogênio. Esses estudos foram de importância fundamental para o desenvolvimento dos primeiros conversores catalíticos comerciais e para o entendimento de reações catalíticas mais complexas, envolvendo misturas gasosas e catalisadores multicomponentes.

\section{OXIDAÇÃO DO MONÓXIDO DE CARBONO}

Os primeiros estudos abordando o abatimento de poluentes causados por fontes móveis tratavam da oxidação do monóxido de carbono sobre óxido de manganês ${ }^{8}$. Neste caso, foi proposto o chamado mecanismo de Roginskii, de acordo com o qual a espécie $\mathrm{MnO}_{2}$ atua como doador de oxigênio e é regenerada pelo oxigênio do fluxo reagente. Este óxido também age como um sítio de reação entre o monóxido de carbono e o oxigênio, na fase adsorvida, como mostram as equações (14) a (19).

$\mathrm{O}_{2(\mathrm{~g})}+\mathrm{MnO}_{2} \rightleftarrows \mathrm{MnO}_{2} \cdot \mathrm{O}_{2}$

$\mathrm{MnO}_{2}+\mathrm{CO}_{(\mathrm{g})} \rightleftarrows \mathrm{MnO}_{2} \cdot \mathrm{CO}$

$\mathrm{MnO}_{2} \cdot \mathrm{CO}+\mathrm{MnO}_{2} \cdot \mathrm{O}_{2} \longrightarrow \mathrm{MnO}_{2} \cdot \mathrm{O}+\mathrm{CO}_{2}$

$\mathrm{MnO}_{2} \cdot \mathrm{O}+\mathrm{CO}_{(\mathrm{g})} \longrightarrow \mathrm{MnO}_{2}+\mathrm{CO}_{2}$

$\mathrm{MnO}_{2} \cdot \mathrm{CO} \longrightarrow \mathrm{MnO}+\mathrm{CO}_{2}$

$2 \mathrm{MnO}+\mathrm{MnO}_{2} \cdot \mathrm{O}_{2} \longrightarrow 3 \mathrm{MnO}_{2}$

Algum tempo depois dos estudos de Roginskii, o óxido de cobre foi reconhecido como um eficiente catalisador de oxidação do monóxido de carbono ${ }^{13}$. O mecanismo proposto para esta reação também considerava a participação do oxigênio da rede, e era consistente com o mecanismo de Roginskii.

Estudos posteriores, usando difração de raios $\mathrm{X}$ do óxido de cobre suportado em alumina, mostraram que os sítios ativos estavam associados com a interface entre as fases $\mathrm{Cu}_{2} \mathrm{O}$ e $\mathrm{Cu}$ e/ou entre as fases $\mathrm{Cu}_{2} \mathrm{O}$ e $\mathrm{Cu}$ não estequiométricas ${ }^{14}$. Os autores restringiram as conclusões a temperaturas na faixa de 100 a $160{ }^{\circ} \mathrm{C}$ e sugeriram que, a temperaturas mais elevadas, a oxidação seria melhor descrita como processos alternativos de oxidação e redução do óxido de cobre.

Outros mecanismos similares foram propostos para reações envolvendo óxidos de cobre e óxidos de zinco dopados com índio como catalisadores ${ }^{15,16}$. Uma versão simplificada do mecanismo de Roginskii foi proposta por Hughes e Hill usando catalisadores à base de vanádio ${ }^{17}$.

Shelef e colaboradores investigaram o desempenho de diversos catalisadores constituídos por metais de transição suportados, na oxidação do monóxido de carbono e concluíram que a etapa determinante, em todos os casos, era a ruptura da ligação oxigêniocatalisador e que a atividade variava na sequência: $\mathrm{CuCr}_{2} \mathrm{O}_{4}=\mathrm{Co}_{3} \mathrm{O}_{4}$ $>\mathrm{Cu}_{2} \mathrm{O}>\mathrm{Fe}_{2} \mathrm{O}_{3}>\mathrm{MnO}>\mathrm{Pt}>\mathrm{NiO}>\mathrm{Cr}_{2} \mathrm{O}_{3}>>\mathrm{V}_{2} \mathrm{O}_{5}$. No caso de catalisadores à base de cromitas de cobre, observou-se que a atividade devia ser atribuída a esse composto e não ao óxido de cobre ou ao óxido cromo isolados, como se supunha anteriormente ${ }^{18}$.

Muitos outros mecanismos propostos com outros catalisadores são versões do mecanismo de Roginskii. Pode-se mostrar, genericamente que, no caso dos metais de transição, existe uma etapa de oxiredução, na qual o catalisador participa diretamente da reação pela transferência e restauração do oxigênio estrutural ou através de uma transferência de carga do catalisador ${ }^{8}$.

A oxidação do monóxido de carbono sobre metais nobres é descrita por alguns mecanismos que diferem pouco uns dos outros, envolvendo uma etapa determinante na qual a espécie $\mathrm{CO}$ fracamente quimissorvida reage com um átomo de oxigênio da superfície ${ }^{19}$.

A partir dos mecanismos propostos na literatura, pode-se concluir que os óxidos de metais de transição podem (e devem) ser desativados, quando usados em sistemas em que há deficiência de oxigênio, uma vez que existe uma etapa envolvendo um mecanismo redox, no qual o catalisador participa diretamente da reação, pela transferência e restauração do oxigênio estrutural. Todavia, em catalisadores de metais nobres, qualquer perda em conversão deve ser temporária e estar diretamente relacionada com a disponibilidade de oxigênio, já que o catalisador não contribui com oxigênio estrutural.

Diversos estudos indicam que os óxidos metálicos são promissores, como substitutos dos metais nobres, em catalisadores automotivos. Vários óxidos de metais de transição já foram testados na oxidação do monóxido de carbono, obtendo-se a ordem de atividade: $\mathrm{CuCr}_{2} \mathrm{O}_{4}=$ $\mathrm{Co}_{3} \mathrm{O}_{4}>\mathrm{Cu}_{2} \mathrm{O}>\mathrm{Fe}_{2} \mathrm{O}_{3}>\mathrm{MnO}>\mathrm{Pt}>\mathrm{NiO}>\mathrm{Cr}_{2} \mathrm{O}_{3}>>\mathrm{V}_{2} \mathrm{O}_{5}^{8}$. $\mathrm{Em}$ outros estudos abordando catalisadores mistos de cobre e de cromo, suportados sobre alumina, na oxidação do monóxido de carbono e na redução do óxido de nitrogênio (NO) pelo monóxido de carbono, em presença de oxigênio, concluiu-se que a presença de oxigênio inibia a redução do óxido nítrico pelo monóxido de carbono ${ }^{20}$. Em baixas concentrações da espécie $\mathrm{SO}_{2}(<150 \mathrm{ppm})$ houve um efeito reversível inibidor da atividade. Esse catalisador apresentou o mesmo desempenho que o catalisador comercial, usado atualmente.

\section{OXIDAÇÃO DE COMPOSTOS ORGÂNICOS VOLÁTEIS}

Até a década de sessenta, os estudos de mecanismos da oxidação de hidrocarbonetos estavam orientados, principalmente, para a oxidação parcial, como conseqüência da importância desses processos nas indústrias petroquímica e de química fina ${ }^{21}$. Contudo, em virtude do crescente interesse pelas questões de poluição ambiental causada pelos gases de exaustão, resultantes da queima de combustíveis, tem-se observado um crescente aumento de publicações abordando a oxidação total.

No caso dos hidrocarbonetos, os estudos adotaram um enfoque distinto daquele da oxidação de monóxido de carbono. No primeiro caso, os trabalhos estão principalmente voltados para a determinação da etapa limitante da reação, baseada em medidas cinéticas e na correlação com a atividade catalítica global e com a atividade intrínseca dos catalisadores.

A oxidação do metano foi extensivamente estudada, encontrando-se que a platina e o paládio eram os catalisadores mais ativos, seguidos pelos óxidos de metais de transição ${ }^{8,22,23}$. Esses trabalhos levaram à proposta de mecanismos similares, que consideravam improvável a existência de produtos de oxidação intermediários ${ }^{22}$.

A oxidação catalítica de outros alcanos, tais como etano, propano, isobutano e butano foi investigada por Hiam e colaboradores ${ }^{24}$. Empregaram um filamento de platina como catalisador e encontraram que a facilidade de oxidação ocorria na ordem etano $<$ propano $\cong$ isobutano $\leq$ butano. Os autores também concluíram que a adsorção dissociativa do hidrocarboneto era a etapa determinante.

Outros hidrocarbonetos, tais como etileno e propileno, também foram estudados. No primeiro caso, observou-se que os óxidos de cobalto e de cromo eram os catalisadores mais ativos e que a energia de ativação poderia refletir, de modo preciso, a atividade intrínse$\mathrm{ca}^{25}$. Entretanto, os dados apresentados pelos autores não eram suficientemente extensivos para sustentar esta afirmação. No caso do propileno, foi conduzida uma ampla investigação por Morooka e Osaki, usando diversos componentes catalíticos (platina, paládio, prata, cobalto, cobre, entre outros) suportados em carbeto de silí$\mathrm{cio}^{26}$. A partir de estudos cinéticos, correlacionaram a velocidade e a ordem da reação com o calor de formação do óxido produzido, em concordância com outros trabalhos ${ }^{27}$.

Num estudo posterior estudou-se a oxidação do propileno e etileno sobre platina, paládio, irídio, rutênio e ródio, suportados em 
sílica. Neste caso, foram feitas correlações entre a atividade catalítica e o caráter $d$ dos catalisadores e entre a atividade catalítica e o raio atômico ${ }^{28}$. Os autores enfatizaram a ordem da atividade catalítica nessas correlações e a utilidade das mesmas.

Uma análise elaborada da oxidação completa de hidrocarbonetos foi conduzida por Barnard e Mitchell, a partir de dados cinéticos obtidos na oxidação de benzeno e n-heptano sobre platina suportada em sílica-gel, na oxidação de benzeno e de cicloexano sobre plati$\mathrm{na}^{29}$. Usando o método de Hougen-Watson, eles propuseram que a etapa limitante era a reação entre o hidrocarboneto e o oxigênio adsorvidos, no caso do benzeno e do n-heptano e a adsorção dissociativa, no caso do cicloexano.

Recentemente, foi estudada a oxidação do metano e do ciclopentano sobre catalisadores do tipo $\mathrm{Pt} / \mathrm{Al}_{2} \mathrm{O}_{3}{ }^{30}$. Observou-se que, no primeiro caso, a atividade não variava muito, enquanto no outro a atividade aumentava com o tamanho da partícula metálica. Em ambas as reações, as energias de ativação não variavam com a dispersão metálica e os resultados foram interpretados com base nos dois mecanismos de reação sobre os sítios da platina: (i) mecanismo de MarsVan-Krevelen, sendo a adsorção dissociativa do oxigênio sobre a platina, a etapa determinante e (ii) mecanismo de LangmuirHinshelwood, em que a etapa determinante é a abstração do primeiro hidrogênio da molécula de metano adsorvida.

A oxidação do metanol, em presença ou não de monóxido de carbono, foi estudada usando-se catalisadores monometálicos à base de ródio, platina, paládio, cobre e prata e sistemas bimetálicos contendo paládio e prata, todos suportados em alumina ${ }^{31,32}$. Na ausência de monóxido de carbono, os catalisadores contendo platina e paládio foram mais ativos que aqueles à base de ródio, sendo observados dióxido de carbono, formiato de metila, formaldeído (no caso da platina, paládio e ródio) e acetona (no caso do ródio) como produtos. Em presença de monóxido de carbono, a atividade dos catalisadores contendo platina ou paládio foi fortemente inibida, enquanto os sistemas contendo ródio, prata e cobre-cromo apresentaram o mesmo comportamento. Isto foi atribuído à maior adsorção do monóxido de carbono pela platina e pelo paládio, em relação ao metanol. Por outro lado, a seletividade dos catalisadores, para a oxidação total do metanol, aumentou na ordem: $\mathrm{Ag}<\mathrm{Pt}<\mathrm{Pd}<\mathrm{Cu}-\mathrm{Cr}<\mathrm{Rh}$. Testes adicionais, conduzidos com o catalisador de platina, em presença de óxido nítrico, mostraram que essa espécie também inibia a oxidação do metanol e suprimia a produção do formiato de metila. Também neste caso, foi sugerido que essa espécie seria fortemente adsorvida pela platina, inibindo a adsorção do metanol. Os catalisadores bimetálicos apresentaram atividade superior aos monometálicos, o que foi atribuído à maior capacidade dos primeiros em promover a quimissorção dissociativa do oxigênio. Um comportamento similar ao do metanol foi observado na oxidação total do formaldeído, usando-se os mesmos catalisadores ${ }^{33}$.

Em um estudo posterior, Vannice e Mao observaram a presença de espécies formiato e dioximetileno, como intermediários, na oxidação do formaldeído sobre catalisadores de prata suportada, ou não, em alumina ou sílica ${ }^{34}$. Os produtos da reação variaram em função do suporte, notando-se a formação de monóxido e dióxido de carbono no caso dos sistemas contendo alumina, e apenas dióxido de carbono nos demais.

Com relação ao etanol, somente a partir de 1979, é que foi investigada a sua oxidação completa; até então, os estudos referiamse apenas à oxidação parcial $^{35}$. Os primeiros trabalhos abordavam catalisadores à base de óxido de cobre suportados, ou não, sobre alumina e platina suportada em alumina ${ }^{36}$. Foram conduzidos estudos da cinética de oxidação, variando-se a concentração de etanol e de oxigênio e avaliando-se o efeito do vapor d'água sobre a velocidade de reação. Observou-se a formação de quantidades apreciáveis de acetaldeído, além de dióxido de carbono, quando os catalisadores à base de cobre foram empregados. Neste caso, a velocidade de oxidação completa diminuiu com o aumento da concentração de álcool e aumentou com a concentração de oxigênio; a velocidade de formação do acetaldeído aumentou significativamente com a concentração de álcool, dependendo levemente da concentração de oxigênio. A introdução de vapor d'água inibiu tanto a oxidação completa como a parcial. A cinética observada, tanto para a oxidação completa como para a parcial, foi similar àquela dos hidrocarbonetos insaturados notando-se, todavia, que a formação de dióxido de carbono ocorria principalmente através da oxidação do produto da oxidação parcial (acetaldeído), como mostra a equação (20).

$$
\mathrm{C}_{2} \mathrm{H}_{5}-\mathrm{OH} \longrightarrow \mathrm{CH}_{3} \mathrm{CHO} \longrightarrow \mathrm{CO}_{2}+\mathrm{H}_{2} \mathrm{O}
$$

Por outro lado, com os catalisadores à base de platina, observouse que as ordens de reação da oxidação completa e parcial foram quase as mesmas; no primeiro caso, obteve-se uma ordem negativa em relação ao oxigênio, enquanto a velocidade de oxidação parcial foi quase independente da concentração de oxigênio. Ambas as reações foram inibidas pelo vapor d'água e produziram pequenas quantidades de ácido acético. O mecanismo proposto, para essas reações, constou de reações paralelas e consecutivas envolvendo o ácido acético e o acetaldeído como intermediários ${ }^{36}$.

Ozkan e colaboradores também estudaram a oxidação do etanol sobre catalisadores à base de óxido de cobre, óxido de cromo e óxido de cobre e cromo suportados em alumina ${ }^{37}$. Os sólidos à base de cromo foram mais ativos que os de cobre a baixas temperaturas, ocorrendo o inverso a altas temperaturas. Os catalisadores contendo cromo produziram principalmente acetaldeído, enquanto aqueles contendo cobre formaram apenas dióxido de carbono a baixas temperaturas. A adição de cromo ao cobre levou a um aumento na produção de acetaldeído.

Além desses, outros metais nobres e óxidos metálicos foram estudados nessa reação, tais como estanho, prata e tungstênio sobre alumina $^{38}$. Concluiu-se que o tungstênio promovia a desidratação do etanol para etileno e éter dietílico, a prata promovia a reação de oxidação do etanol para acetaldeído e dióxido de carbono preferencialmente e o estanho catalisava as duas reações, levando à obtenção de acetaldeído e éter dietílico. Outros trabalhos, conduzidos sobre catalisadores à base de platina, paládio, ródio, prata e óxidos de cobre, cromo, manganês, vanádio, níquel e ferro suportados em alumina ou zircônia, mostraram que na oxidação total a atividade decrescia na ordem $\mathrm{Pt}>\mathrm{Pd}>\mathrm{Ag}>\mathrm{Rh}$, enquanto na oxidação parcial a atividade crescia na ordem $\mathrm{Pt}<\mathrm{Pd}<\mathrm{Rh}<\mathrm{Ag}^{39}$. De modo geral, os catalisadores à base de óxidos foram menos ativos que aqueles contendo platina ou paládio na forma metálica. Os catalisadores suportados em alumina foram mais ativos que aqueles suportados em zircônia, o que foi atribuído à maior dispersão metálica dos primeiros. Em todos os casos, com exceção do ródio, verificou-se que a presença de água inibiu a oxidação do etanol.

Outros estudos, conduzidos com catalisadores à base de cromo $\mathrm{e}$ cobre, platina e manganês suportados em alumina, mostraram que os principais produtos foram monóxido e dióxido de carbono (principalmente) e acetaldeído e, o catalisador contendo platina foi o mais ativo $^{40}$. Este comportamento foi explicado admitindo-se que, no caso, dos catalisadores menos ativos, as espécies intermediárias eram mais estáveis que nos sistemas contendo platina.

A oxidação do etanol e do formaldeído foi estudada sobre catalisadores de trióxido de molibdênio e molibdato de ferro, observando-se que a água (produto da reação) e o metanol retardavam a oxidação posterior do formaldeído ${ }^{41}$. Resultado semelhante foi obtido no estudo do efeito da água sobre a oxidação do monóxido de 
carbono usando óxidos de metais de transição; neste caso, a atividade era diminuída e a ordem de reação em relação ao monóxido de carbono era aumentada ${ }^{8}$.

Em um trabalho mais recente, Miyadera estudou a reação de oxidação do etanol em presença de óxido nítrico, oxigênio e água, usando catalisadores de prata suportados em alumina, observando que a mais elevada atividade e seletividade ao nitrogênio ocorriam a $400{ }^{\circ} \mathrm{C}^{42}$. A redução do óxido nítrico pelo etanol, em excesso de oxigênio, foi atribuída às espécies isocianato $(\mathrm{NCO})$ na superfície do catalisador. Esta proposta já havia sido sugerida por Ukisu estudando os mesmos sistemas e usando técnicas de espectroscopia no infravermelho in situ ${ }^{43}$.

Os óxidos de molibdênio também foram avaliados na oxidação do etanol. Investigando-se a influência do suporte, no desempenho desses sistemas, Zhang et al. estudaram catalisadores contendo sílica, alumina e óxido de titânio, variando a concentração do óxido de molibdênio ${ }^{44}$. Usando uma corrente gasosa constituída de etanol, oxigênio e hidrogênio, os autores observaram a produção de acetaldeído, etileno, éter dietílico e óxidos de carbono e notaram que a atividade dos catalisadores decrescia na ordem titânia $>$ alumina $>$ sílica. Essa reatividade foi atribuída à interação molibdato-suporte, mais intensa no caso da titânia e menos forte na sílica, assim como à redutibilidade das espécies molibdato, já que essas espécies se reduzem mais facilmente quando suportadas em titânia e mais dificilmente quando suportadas em sílica. Resultados similares foram obtidos por Kikutani ${ }^{45,46}$.

Esses trabalhos mostraram que a presença de outros compostos, tais como monóxido de carbono, óxido nítrico e água, cujas presenças são comuns na descarga de veículos leves, pode alterar significativamente o desempenho dos catalisadores na oxidação total de compostos orgânicos.

A partir desses estudos, pode-se dividir os catalisadores usados na oxidação de compostos orgânicos voláteis em três classes principais: óxidos metálicos simples ou mistos, metais nobres suportados e combinações de metais nobres/óxidos metálicos ${ }^{47}$. Os mais utilizados são metais nobres (platina, paládio, ródio) e óxidos de metais de transição (cobre, titânio, vanádio, cobalto, níquel, manganês) que são também, em geral, eficientes na oxidação do monóxido de carbono ${ }^{48}$.

Em geral, a alta atividade exigida nos processos de oxidação requer metais que possam assumir mais que um estado de valência e, portanto, possam participar de reações redox. Dessa forma, os óxidos de metais de transição são os mais ativos, sendo esta propriedade determinada pela configuração eletrônica do nível $d$ do metal ${ }^{32}$. A atividade máxima é encontrada no caso de íons com três, seis e oito elétrons no orbital $d$. As misturas de óxidos, em geral, exibem maior atividade e estabilidade que os óxidos simples ${ }^{8}$.

Nas reações de oxidação, são geralmente usados os óxidos dos metais dos grupos 6 até 11 da tabela periódica. Quando comparados aos metais nobres suportados, esses catalisadores apresentam menor custo e maior resistência ao envenenamento. Entretanto, exigem velocidades espaciais mais baixas ${ }^{48}$. Como regra geral, eles são menos ativos que os metais nobres, especialmente se for considerada a atividade por átomo metálico. Todavia, nas condições de exaustão dos automóveis, essas atividades são comparáveis ${ }^{47}$.

A partir de estudos com diversos óxidos e metais, observou-se que a platina e o paládio apresentam alta atividade e boa estabilidade, seguidos por óxidos de metais de transição, embora estes não sejam estáveis ${ }^{8}$. Na temperatura de operação, os metais tendem a sinterizar rapidamente ou formar óxidos inativos. No caso da oxidação do monóxido de carbono e hidrocarbonetos, o óxido de cobalto $\left(\mathrm{Co}_{3} \mathrm{O}_{4}\right)$, óxido de níquel ( $\left.\mathrm{NiO}\right)$ e de cromo $\left(\mathrm{Cr}_{2} \mathrm{O}_{3}\right)$ são os mais promissores. Os resultados obtidos com óxidos binários foram os melhores, e os óxidos de metais de transição apresentaram maior ativi- dade e estabilidade que os demais, embora existam algumas exceções. A atividade desses catalisadores é afetada pela presença de promotores, pela dispersão da fase ativa e pela técnica empregada na deposição da fase ativa, dentre outros fatores ${ }^{2}$. Até a década de setenta, foram conduzidos vários estudos de oxidação sobre óxidos metálicos, que diminuíram significativamente nas últimas décadas, em virtude das vantagens oferecidas pelos catalisadores suportados ${ }^{7}$. Todavia, devido à escassez dos metais nobres e à necessidade de diminuir os custos dos catalisadores automotivos, o interesse pelo estudo dos óxidos metálicos foi renovado.

Vários outros metais nobres são também ativos para a oxidação. Entretanto, o uso de outros metais além da platina e do paládio é restrito, devido à sua facilidade de reagir com o suporte e à oferta limitada. Comparados aos óxidos metálicos, os metais nobres têm certas vantagens, como maior atividade específica para a oxidação de hidrocarbonetos, maior resistência à perda de atividade a baixas temperaturas e menor desativação por enxofre, abaixo de $500{ }^{\circ} \mathrm{C}^{47}$. Além disso, são usados em pequenas quantidades, entre $0,1-0,5 \%$ em peso, pois são preparados por dispersão em um grande número de suportes $^{49}$.

Apesar dessas vantagens, a platina e o paládio sinterizam rapidamente, entre $500-900{ }^{\circ} \mathrm{C}$, o que reduz a atividade catalítica. Além disso, em atmosfera oxidante, esses metais podem dispersar-se como óxidos sobre a superfície do suporte, em temperaturas inferiores àquelas de decomposição dos óxidos $\left(\mathrm{PtO}_{2}=585^{\circ} \mathrm{C} ; \mathrm{PdO}=790{ }^{\circ} \mathrm{C}\right)$ ou até em valores mais altos, se o complexo formado entre o óxido e a superfície do suporte possuir estabilidade suficiente nesta condição ${ }^{2}$.

A platina é um dos principais componentes dos catalisadores de exaustão de automóveis e é largamente aplicada a gases contendo estritamente hidrocarbonetos e compostos orgânicos oxigenados, uma vez que esse metal é envenenado por hidrocarbonetos clorados. A desativação pelo ácido clorídrico prevalece abaixo de $350{ }^{\circ} \mathrm{C}$ e é reversível em muitos casos, podendo ser superada por uma carga de platina maior que $0,3 \%$. Por outro lado, o enxofre retido sobre o catalisador de metal nobre pode ser dessorvido em condições oxidantes, em temperaturas superiores a $700{ }^{\circ} \mathrm{C}$, algumas vezes com pouca perda de atividade ${ }^{8}$.

O paládio é também um importante componente dos catalisadores automotivos. Um exemplo é o emprego desse metal sobre alumina, na oxidação do propano e propeno, em que se usou cloreto como sal precursor, que atuou como veneno do catalisador, principalmente em condições oxidantes ${ }^{50}$. Depois de sucessivos ciclos de oxidação, o efeito do envenenamento do cloro desapareceu, como consequiência da sua remoção pela água produzida durante a combustão. Quando a quantidade de água foi equivalente àquela contida nos gases de exaustão, a oxidação dos hidrocarbonetos foi inibida. O mesmo resultado foi obtido com a platina. $\mathrm{O}$ enxofre desativou fortemente os catalisadores de paládio sobre sílica ou alumina e a extensão da desativação foi independente do suporte porém, com a alumina, a velocidade de desativação foi menor, pois ela adsorveu as espécies sulfato, o que não aconteceu com a sílica ${ }^{51}$.

Estudando a oxidação catalítica do metano sobre catalisadores do tipo $\mathrm{Pd} / \mathrm{Al}_{2} \mathrm{O}_{3}$, Briot concluiu que esta reação é dependente do diâmetro das partículas metálicas e que o paládio está na forma de óxido em temperaturas de reação superiores a $400{ }^{\circ} \mathrm{C}$, em misturas de reação ricas em oxigênio ${ }^{52}$. Foi verificado também que a reação ocorre sobre esta fase, mesmo se o catalisador estiver inicialmente na forma reduzida, ao contrário do que ocorre com o catalisador Pt/ $\mathrm{Al}_{2} \mathrm{O}_{3}$. Resultados concordantes foram encontrados por Garbowski, confirmando que a combustão catalítica depende da estrutura da superfície $^{53}$.

O paládio pode também ser combinado com a platina para formar um catalisador bimetálico, que é a base para o controle na 
exaustão dos gases dos automóveis, em que as temperaturas e as velocidades espaciais são normalmente mais altas do que em sistemas típicos de controle de compostos orgânicos voláteis ${ }^{54}$. Observou-se que pequenas quantidades de platina promovem a completa oxidação do monóxido de carbono e do xileno sobre paládio, enquanto o paládio não promove a oxidação dos mesmos materiais sobre a platina ${ }^{55}$.

A elevada atividade da platina e do paládio está relacionada à sua habilidade em ativar o hidrogênio, o oxigênio e as ligações $\mathrm{C}-\mathrm{H}$ e O-H. Na oxidação do monóxido de carbono, olefinas e metano, o paládio é o mais ativo, enquanto que no caso dos hidrocarbonetos aromáticos e parafínicos, com mais de três átomos de carbono, a platina é mais ativa ${ }^{47}$.

A presença de pequenas quantidades de metais nobres pode aumentar o desempenho de certos catalisadores à base de óxidos metálicos. Por isso, são comuns os relatos sobre catalisadores mistos, isto é, contendo metais nobres e óxidos de outros metais, principalmente de transição. Um exemplo interessante envolve o uso de platina em óxidos mistos com estruturas do tipo perovisquitas ${ }^{56}$. Neste caso, observou-se que a presença do metal nobre aumentava a resistência do material ao envenenamento pelo enxofre.

Vários catalisadores bimetálicos suportados sobre alumina foram usados na oxidação do formaldeído. Considerando um metal não-nobre como o outro componente, a ordem de atividade foi $\mathrm{CuO}$ $>\mathrm{CoO}>\mathrm{MnO}$; no caso de metais nobres, a atividade foi mais elevada, sendo $\mathrm{AgO}>\mathrm{PdO}$. Os catalisadores bimetálicos do tipo $\mathrm{Cu}-\mathrm{Mn}$ $\mathrm{O}, \mathrm{Cu}-\mathrm{Co}-\mathrm{O}$ e $\mathrm{Pd}-\mathrm{Ag}$ foram mais ativos que aqueles com um único metal, sendo o sistema Pd-Ag/alumina o mais eficiente. A atividade dos catalisadores do tipo $\mathrm{Cu}-\mathrm{Mn}-\mathrm{O}$ e $\mathrm{Cu}-\mathrm{Co}-\mathrm{O}$ foi aumentada pela adição de prata, enquanto a adição de cério e paládio ao sistema $\mathrm{Cu}$ Ag-Mn-O provocou um aumento ainda maior da atividade ${ }^{56}$. A adição do cobre à platina também provocou uma melhoria no desempenho, o que foi atribuído à formação de uma liga entre a platina e o cobre $^{57}$.

Por outro lado, Vassileva estudou a estrutura do $\mathrm{Pd}-\mathrm{V}_{2} \mathrm{O}_{5} / \mathrm{Al}_{2} \mathrm{O}_{3}$, na oxidação total de hidrocarbonetos, e verificou a ocorrência de um efeito sinérgico entre os dois componentes ativos do sistema sobre a atividade catalítica ${ }^{58}$.

A atividade dos catalisadores bimetálicos pode ser ainda aumentada, usando técnicas de preparação não convencionais, como por exemplo reações controladas de superfície e reação redox direta, utilizadas na obtenção de sistemas do tipo $\mathrm{Pt}-\mathrm{Pd} / \gamma-\mathrm{Al}_{2} \mathrm{O}_{3}$, usadas na oxidação do propano ${ }^{59}$.

O suporte é outro importante fator a ser considerado. Recentemente, Bozo e colaboradores estudaram o efeito do suporte na oxidação total de hidrocarbonetos, usando propano como molécula modelo $^{60}$. Os catalisadores empregados foram à base de platina suportada em soluções sólidas de óxidos de cério e de zircônio. Observouse uma rápida desativação do catalisador, que foi atribuída à presença de espécies oxidadas ligadas ao suporte e/ou ao metal.

Um trabalho recente mostrou que o óxido de manganês $\left(\gamma-\mathrm{MnO}_{2}\right)$ é um catalisador promissor para a oxidação de hidrocarbonetos, sendo mais ativo e, em muitos aspectos, superior ao catalisador convencional $^{61}$. O sistema sofre sinterização e uma redução parcial, mas estes efeitos são limitados e não afetam a sua atividade e seletividade, em testes de laboratório.

Apesar da descoberta de tantos sistemas eficientes, a maior contribuição para o desenvolvimento de catalisadores de oxidação total dos compostos orgânicos provém dos monólitos ativos. Esses sistemas são constituídos por uma estrutura cerâmica de alta resistência térmica e mecânica (monólito), sobre qual se deposita o suporte (em uma fina camada), o componente ativo e os promotores. Este catalisador resolve muitos dos problemas inerentes a sistemas de metais nobres e óxidos, como por exemplo a aglomeração e volatilização dos metais ${ }^{1}$.

\section{REDUÇÃO DE ÓXIDOS DE NITROGÊNIO}

Os óxidos de nitrogênio (representados genericamente por NOx), emitidos pelas fontes de combustão, estão principalmente na forma de óxido nítrico (NO); menos de 5\%, em geral, estão como dióxido de nitrogênio $\left(\mathrm{NO}_{2}\right)$. Estes compostos são formados pela oxidação do nitrogênio atmosférico, em temperaturas próximas àquelas geradas na queima de combustíveis ou pela oxidação de outros compostos de nitrogênio presentes no combustível ${ }^{2}$. Em geral, os conversores catalíticos, contendo metais nobres, levam a altas conversões do nitrogênio presente no combustível para óxidos de nitrogênio (50$90 \%)^{7,62}$. São aceitos três mecanismos para a formação de NOx: (i) mecanismo Zeldovich (formação térmica de NOx); (ii) mecanismo de radicais livres e (iii) mecanismo de oxidação dos compostos de nitrogênio presentes nos combustíveis.

O mecanismo proposto por Zeldovich considera a formação do óxido nítrico através das etapas descritas pelas equações (21) a (24). Essas reações são fortemente dependentes da temperatura e só são significativas em temperaturas superiores a $1500{ }^{\circ} \mathrm{C}^{7}$.

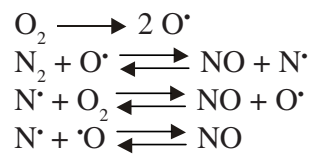

O mecanismo de radicais livres geralmente ocorre quando a concentração de hidrocarbonetos é alta. Neste caso, há o ataque do carbono ou radicais de hidrocarbonetos às moléculas de nitrogênio, de acordo com as equações (25) a (27).

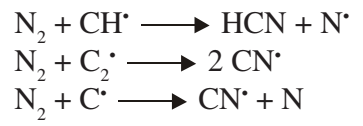

Os compostos de nitrogênio, presentes na exaustão de automóveis, podem ser originários das reações mencionadas anteriormente, ou podem provir de moléculas nitrogenadas presentes nos combustíveis. No último caso, se a razão combustível/ar é baixa, produz-se óxidos de nitrogênio, enquanto se a razão for elevada, são produzidos amônia e oxigênio. Em misturas ricas em hidrocarbonetos, os compostos de nitrogênio em fase gasosa são rapidamente convertidos a ácido cianídrico. Este é convertido a espécies aminas $\left(\mathrm{NH}_{\mathrm{i}}\right)$ as quais são oxidadas a $\mathrm{NO}$, ou convertidas a nitrogênio por reações com $\mathrm{NO}$ ou outras espécies $\mathrm{NH}_{\mathrm{i}}{ }^{63}$.

Qualquer que seja a fonte, ao chegar à atmosfera a espécie NO é convertida a $\mathrm{NO}_{2}$ através das reações (28) a (30) ${ }^{7}$.

$2 \mathrm{NO}+\mathrm{O}_{2} \longrightarrow 2 \mathrm{NO}_{2}$
$\mathrm{NO}+\mathrm{O} \longrightarrow \mathrm{NO}_{2}+\mathrm{O}_{2}$
$\mathrm{NO}+\mathrm{HO}_{2} \cdot \mathrm{NO}_{2}+\mathrm{OH}^{\cdot}$

No estudo da remoção dos óxidos de nitrogênio, assim como no caso das reações de oxidação do monóxido de carbono e hidrocarbonetos, existe a dificuldade de reproduzir em laboratório as reações que ocorrem na exaustão dos automóveis. No caso dos óxidos de nitrogênio, existe uma complexidade adicional associada às diversas formas em que o nitrogênio pode estar presente, como óxidos ou na forma de nitrogênio ligado a carbono, como por exemplo como aminas ou nitrocompostos, provenientes dos combustíveis. 
Os óxidos de nitrogênio podem ser removidos dos gases de combustão por redução, podendo-se usar um hidrocarboneto, hidrogênio ou monóxido de carbono, ou se o oxigênio estiver em excesso no fluxo gasoso, um agente redutor seletivo como a amônia ${ }^{2}$. Uma outra forma de remoção é a sua decomposição direta em nitrogênio e oxigênio, porém esta reação é extremamente desfavorecida pela cinética, o que a torna sem importância prática no tratamento dos gases de exaustão. Já no caso da redução do óxido nítrico com vários agentes, há o favorecimento termodinâmico do processo e a cinética tem importância prática ${ }^{8}$.

A redução da espécie NO pelo monóxido de carbono é uma das reações mais importantes entre aquelas que ocorrem nos conversores catalíticos, uma vez que as duas espécies estão presentes como poluentes. Em geral, admite-se que o mecanismo de redução do óxido nítrico com monóxido de carbono, sobre óxidos de metais de transição, seja do tipo indicado pelas equações (31) e (32) ${ }^{18}$.

$\mathrm{CO}+$ cat. oxidado $\longrightarrow \mathrm{CO}_{2}+$ cat. reduzido
$\mathrm{NO}+$ cat. reduzido $\longrightarrow 1 / 2 \mathrm{~N}_{2}+$ cat. oxidado

Observou-se que a reatividade dos óxidos decresce na ordem $\mathrm{Fe}_{2} \mathrm{O}_{3}>\mathrm{Cu}_{2} \mathrm{O}>\mathrm{Cr}_{2} \mathrm{O}_{3}>\mathrm{NiO}>\mathrm{Co}_{3} \mathrm{O}_{4}>\mathrm{MnO}_{2}>\mathrm{V}_{2} \mathrm{O}_{5}{ }^{18}$. Entretanto, a análise dos resultados publicados leva à conclusão de que o mecanismo é mais complexo, pois a temperaturas inferiores a $300{ }^{\circ} \mathrm{C}$ formam-se quantidades apreciáveis da espécie $\mathrm{N}_{2} \mathrm{O}$, indicando alguma forma de interação entre duas moléculas de óxido nítrico e a superfície catalítica.

Em um estudo realizado usando cobre suportado sobre óxido de titânio, na reação de redução do óxido nítrico pelo monóxido de carbono, concluiu-se que a redução da amostra a baixas temperaturas conduzia à formação de dióxido de carbono, mas a reação só se completava a $473 \mathrm{~K}^{64}$. Em temperaturas elevadas, detectou-se grandes quantidades das espécies $\mathrm{N}_{2} \mathrm{O}$ e $\mathrm{CO}$. Neste caso, a atividade foi relacionada à facilidade de dissociação das moléculas de $\mathrm{NO}$, determinada por uma transferência de elétrons ao óxido de titânio reduzida para orbitais anti-ligantes $d$ na molécula do NO. Observou-se que os sítios do cobre reduzido ativavam o monóxido de carbono.

Em outro trabalho, usando catalisadores à base de cobalto suportado em alumina, Yamaguchi et al. ${ }^{65}$ observaram que as moléculas de óxido nítrico eram adsorvidas em sítios de $\mathrm{Co}^{3+}$ para formar dinitrosilas de cobalto, enquanto as moléculas de monóxido de carbono não eram adsorvidas. Estas últimas, no entanto, promoviam a adsorção do óxido nítrico, a reatividade das nitrosilas de cobalto e alterações na estrutura da nitrosila.

Os efeitos de interação metal-suporte, na eliminação de espécies $\mathrm{NO}$ e CO em presença de oxigênio, foram recentemente estudados, usando-se catalisadores à base de paládio e paládio-cobre, suportados em céria sobre alumina e céria-zircônia sobre alumina ${ }^{66}$. Observou-se que o desempenho dos catalisadores é dominado pelas propriedades da interação metal-suporte, notando-se que os catalisadores à base de platina apresentaram comportamentos similares, enquanto o cobre modificou apenas o comportamento dos catalisadores suportados em céria sobre alumina.

O hidrogênio também pode estar presente nos gases de exaustão, tornando possível as reações indicadas pelas equações (33) a $(35)^{67}$.

$$
\begin{aligned}
& \mathrm{NO}+\mathrm{H}_{2} \longrightarrow 1 / 2 \mathrm{~N}_{2}+\mathrm{H}_{2} \mathrm{O} \\
& 2 \mathrm{~N}+5 \mathrm{H}_{2} \longrightarrow 2 \mathrm{NH}_{3}+2 \mathrm{H}_{2} \mathrm{O} \\
& 2 \mathrm{NO}+\mathrm{H}_{2} \longrightarrow \mathrm{N}_{2} \mathrm{O}+\mathrm{H}_{2} \mathrm{O}
\end{aligned}
$$

O mecanismo de redução do óxido nítrico por hidrogênio, sobre óxidos de metais de transição, pode ser do tipo redox, a altas temperaturas; todavia, a presença de amônia, nos produtos, em temperatu- ras baixas, é indicativa da interação entre o hidrogênio adsorvido e a espécie NO. No caso de metais nobres, a reação ocorre entre espécies adsorvidas quimicamente, mas não existem estudos detalhados sobre a natureza das espécies adsorvidas e os possíveis caminhos de reação ${ }^{8}$.

A reação do óxido nítrico com hidrocarbonetos tem se apresentado como uma opção conveniente para conversores catalíticos, uma vez que elimina dois poluentes simultaneamente. A reação produz nitrogênio, dióxido de carbono e água, além de monóxido de carbono e de espécies $\mathrm{N}_{2} \mathrm{O}$, estas últimas resultantes da queima incompleta. Embora bem estudado, o mecanismo dessa reação ainda é objeto de controvérsias na literatura, existindo propostas contraditórias. Para alguns autores, o mecanismo envolve uma etapa de adsorção do óxido nítrico, anterior à sua decomposição e a regeneração dos sítios ocorre através da redução do oxigênio adsorvido pelo hidrocarboneto ${ }^{68}$. Para outros, a etapa principal é a transferência do óxido nítrico em dióxido de nitrogênio, uma espécie intermediária que posteriormente oxida espécies orgânicas adsorvidas, tais como nitroespécies, nitritos e carbonilas, em presença de oxigênio, a nitrogênio, dióxido de nitrogênio e dióxido de carbono ${ }^{8}$. Por outro lado, Bamwenda et al. investigaram os intermediários de superfície e encontraram hidrocarbonetos, isocianatos e cianetos. Eles propuseram que as espécies $\mathrm{N}-\mathrm{CO}$ seriam os compostos intermediários da reação ${ }^{69}$. Recentemente, outros estudos mostraram que o sistema binário $\mathrm{SnO}_{2} / \gamma-\mathrm{Al}_{2} \mathrm{O}_{3}$ é um catalisador promissor para a redução seletiva de óxidos de nitrogênio pelo propano ${ }^{70}$. O hidrocarboneto é ativado nos sítios do óxido de estanho para formar intermediários oxigenados, tais como acroleína e acetaldeído que, subseqüentemente, reagem com os óxidos de nitrogênio para produzir nitrogênio.

Outra opção conveniente para eliminar os óxidos de nitrogênio é utilizar compostos orgânicos oxigenados (tal como etanol) presentes nos gases de exaustão. Um trabalho recente mostrou que essas misturas, em presença ou não de excesso de oxigênio, sobre catalisadores do tipo $\mathrm{Ag} / \mathrm{Al}_{2} \mathrm{O}_{3}$ produziam espécies isocianato que reagiam com a mistura $\mathrm{NO}+\mathrm{O}_{2}$ ou oxigênio para formar nitrogênio ${ }^{71}$. Notou-se que a presença de oxigênio aumentava drasticamente a formação de nitrogênio.

Os catalisadores à base de platina têm sido universalmente aceitos como os mais ativos para a redução de óxidos de nitrogênio. Estudos conduzidos com misturas de propano, oxigênio, óxido nitroso e óxido nítrico sobre diversos catalisadores metálicos mostraram que a platina é o metal mais ativo ${ }^{72}$. Em experimentos individuais, foi observada uma ampla variação da reatividade dos oxidantes, que foi alterada nas misturas, devido a interações mútuas. Este comportamento foi atribuído a uma competição entre os oxidantes, especialmente usando-se a platina e o paládio. Outros trabalhos, em que foram usados alumina e zeólitas como suportes, também mostraram a superioridade da platina em relação aos outros metais ${ }^{73}$.

Além da platina, o paládio e o ródio também foram extensivamente estudados na redução dos óxidos de nitrogênio. Mello et al. estudaram a redução do óxido nítrico em presença de metano e etano, usando catalisadores à base de paládio e molibdênio, concluindo que a presença de óxido de molibdênio $\left(\mathrm{MoO}_{3}\right)$ aumentava a seletividade para a formação de nitrogênio, na reação conduzida a $593 \mathrm{~K}^{74}$.

Além dos catalisadores metálicos, diversos óxidos foram avaliados na redução de óxidos de nitrogênio, tais como óxido de titânio $\left(\mathrm{TiO}_{2}\right)$, ferro $\left(\mathrm{Fe}_{2} \mathrm{O}_{3}\right)$ ou alumínio $\left(\mathrm{Al}_{2} \mathrm{O}_{3}\right)$. O primeiro apresentou alta atividade e seletividade e resistência ao envenenamento por enxofre, além de ser regenerável. Os outros dois apresentaram alta seletividade até $450{ }^{\circ} \mathrm{C}$, porém a atividade foi inferior à do óxido de titânio, além de serem mais facilmente envenenados por enxofre e não poderem ser regenerados. Como segundo componente foram usados os óxidos de vanádio $\left(\mathrm{V}_{2} \mathrm{O}_{5}\right)$, molibdênio $\left(\mathrm{MoO}_{3}\right)$, tugnstênio 
$\left(\mathrm{WO}_{3}\right)$, ferro $\left(\mathrm{Fe}_{2} \mathrm{O}_{3}\right)$, cobalto $(\mathrm{CoO})$, níquel $(\mathrm{NiO})$, manganês $\left(\mathrm{MnO}_{2}\right)$, cromo $\left(\mathrm{Cr}_{2} \mathrm{O}_{3}\right)$ e cobre $(\mathrm{CuO})^{75}$.

Outros catalisadores continuam a ser investigados na decomposição do óxido nítrico. Sistemas à base de óxidos de cobre e manganês foram avaliados por Spassova e colaboradores, que observaram que quando a conversão ocorria em ausência de oxigênio, parte deste era liberada levando à oxidação secundária do óxido nítrico adsorvido para formar dióxido de nitrogênio ${ }^{76}$. Não se detectou a formação de óxido nitroso nem a oxidação homogênea do óxido nítrico em presença de oxigênio.

Zeólitas do tipo ZSM-5 contendo cobre ou ferro também são apontadas como catalisadores eficientes nessa reação. Recentemente, observou-se que o catalisador Fe/ZSM-5, preparado por deposição química a vapor, apresentou atividade mais estável e maior resistência ao envenenamento pelo enxofre na redução do óxido nítrico com propano, quando comparado com o mesmo catalisador preparado por métodos convencionais (troca iônica ou impregnação) ${ }^{69,77}$.

\section{TECNOLOGIA NA REMOÇÃO DE POLUENTES DA EXAUSTÃO DE AUTOMÓVEIS}

Os primeiros conversores comerciais, utilizados no período de 1976 a 1979, removiam apenas monóxido de carbono e hidrocarbonetos. Os níveis de emissão de óxidos de nitrogênio, exigidos naquela época, eram alcançados reciclando-se o gás de exaustão que diluía o gás de combustão e diminuía a temperatura de chama da combustão, resultando numa menor produção térmica desses compostos, como previsto pelo mecanismo de Zeldovich. O motor operava com uma mistura com composição superior à estequiométrica, para reduzir ainda mais a formação do óxido nítrico, e ar secundário era introduzido no gás de exaustão para prover oxigênio suficiente para a oxidação catalítica do monóxido de carbono e hidrocarbonetos $^{11}$.

Nesse período, muitos materiais catalíticos foram estudados, tais como platina, paládio, cobre, cromo, níquel e manganês, entre outros. Os dois primeiros foram reconhecidos como excelentes catalisadores de oxidação, mas os outros metais possuíam custos consideravelmente mais baixos e maior disponibilidade. Dessa forma, muitos metais, tais como cobre, cromo, níquel e manganês, entre outros, foram avaliados para uma aplicação comercial ${ }^{10,39}$.

$\mathrm{O}$ desempenho desses materiais pode ser comparado através do dados da Tabela 2, que mostra as atividades relativas de sistemas à base de platina e paládio, comparadas àquelas dos óxidos de metais não nobres, em condições simuladas de exaustão de poluentes a $300{ }^{\circ} \mathrm{C}^{10}$. Pode-se observar que os metais preciosos são consideravelmente mais ativos que os demais e que a atividade depende do

Tabela 2. Comparação das atividades relativas de catalisadores metálicos na remoção de diferentes poluentes ${ }^{10}$

\begin{tabular}{llll}
\hline Poluente & $1 \% \mathrm{CO}$ & $0,1 \% \mathrm{C}_{2} \mathrm{H}_{5}$ & $0,1 \% \mathrm{C}_{2} \mathrm{H}_{6}$ \\
\hline $\mathrm{Pd}$ & 500 & 100 & 1 \\
$\mathrm{Pt}$ & 100 & 12 & 1 \\
$\mathrm{Co}_{2} \mathrm{O}_{3}$ & 80 & 0,6 & 0,05 \\
$\mathrm{CuO} \cdot \mathrm{Cr}_{2} \mathrm{O}_{3}$ & 40 & 0,8 & 0,02 \\
$\mathrm{Au}$ & 15 & 0,3 & $<0,2$ \\
$\mathrm{MnO}_{2}$ & 4,4 & 0,04 & \\
$\mathrm{CuO}$ & 45 & 0,6 & \\
$\mathrm{LaCoO}_{3}$ & 35 & 0,03 & \\
$\mathrm{Fe}_{2} \mathrm{O}_{3}$ & 0,4 & 0,006 & \\
$\mathrm{Cr}_{2} \mathrm{O}_{3}$ & 0,03 & 0,004 & \\
$\mathrm{NiO}$ & 0,013 & 0,0007 & \\
\hline
\end{tabular}

poluente a ser removido. Por exemplo, o paládio é o mais ativo na oxidação do monóxido de carbono, mas é tão ativo quanto a platina na oxidação do etano. Portanto, esses metais seriam os preferidos para compor os catalisadores automotivos, se não fosse o seu alto custo e a baixa disponibilidade. Os óxidos metálicos poderiam ser viáveis, mas a sua baixa atividade exigiria reatores de volumes maiores (velocidades espaciais mais baixas) acarretando problemas no projeto do sistema de exaustão. Além disso, eles são muito susceptíveis ao envenenamento por enxofre $9,78,79$.

Todavia, apesar do alto custo desses metais, as primeiras gerações de catalisadores de oxidação continham uma combinação de platina e paládio e operavam numa faixa de temperatura de 250 a $600{ }^{\circ} \mathrm{C}$, com velocidades espaciais variando entre 10.000 e $100.000 \mathrm{~L} / \mathrm{h}$. As composições típicas incluíam platina e paládio, numa razão entre 2,5:1 e $5: 1$ (cerca de $0,05 \%$ de metais preciosos totais suportados em alumina) e numa quantidade de 0,002 a 0,003 g por veículo ${ }^{11}$.

Esses catalisadores apresentaram diversos problemas de desativação, decorrentes das impurezas presentes nos gases de exaustão, tais como óxidos de enxofre e chumbo tetraetila provenientes da gasolina, e fósforo e zinco oriundos do óleo lubrificante ${ }^{2,80}$. Entre esses venenos o chumbo apresentou-se como o mais severo, mesmo a níveis de traços. A desativação do catalisador foi atribuída à formação de ligas do tipo $\mathrm{Pt}-\mathrm{Pb}$ ou $\mathrm{Pd}-\mathrm{Pb}$, produzidas nas condições da exaustão $\left(900{ }^{\circ} \mathrm{C}\right.$, presença de ar), com baixa atividade catalítica ${ }^{11}$.

Paralelamente aos esforços dos pesquisadores em aumentar a resistência dos catalisadores automotivos aos compostos de chumbo, houve uma crescente conscientização dos severos efeitos desse metal no ambiente e no ser humano. Isto levou à substituição do chumbo tetraetila, por volta de 1970, pelo éter metil-terc-butílico (MTBE), como aditivo à gasolina comercial. Isto tornou o uso de catalisadores à base de platina e paládio mais factível, permitindo que o mesmo atingisse um desempenho de $81500 \mathrm{Km}^{11}$. Todavia, ainda persistiram os problemas de envenenamento pelo fósforo e pelo enxofre, assim como as altas temperaturas de trabalho (800 e $1000{ }^{\circ} \mathrm{C}$ ), como principais causas de desativação dos catalisadores.

Com relação ao efeito da temperatura sobre a estabilidade dos sistemas à base de platina e paládio, observou-se que o catalisador perdia atividade (inicialmente alta) como resultado da sinterização do suporte (alumina). A caracterização do catalisador parcialmente desativado mostrou que o sólido sofria intensa sinterização, acompanhada de uma mudança da fase do suporte, sendo produzida $\alpha$ $\mathrm{Al}_{2} \mathrm{O}_{3}$ de baixa área específica. Neste processo, a estrutura altamente porosa da $\gamma-\mathrm{Al}_{2} \mathrm{O}_{3}$ colapsava e ocluía as espécies catalíticas ativas, tornando-as inacessíveis aos reagentes, como mostrado na Figura $2^{11}$. Devido às excelentes propriedades da alumina como suporte, as

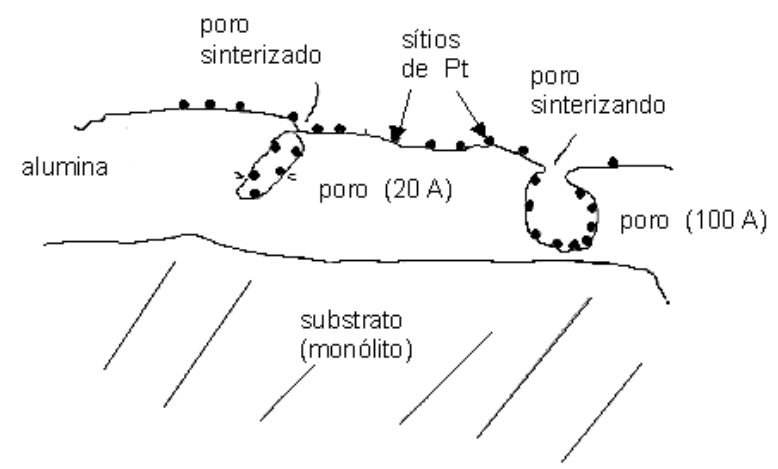

Figura 2. Esquema de sinterização do suporte de um catalisador automotivo ${ }^{11}$ 
pesquisas foram direcionadas para aumentar a sua estabilidade térmica. Esses estudos mostraram que pequenas quantidades de óxido de lantânio, bário e silício reduziam a sinterização da alumina, resultando em catalisadores com áreas de 150-175 $\mathrm{m}^{2} \cdot \mathrm{g}^{-1}$. Entretanto, esse procedimento não solucionou o problema de sinterização do componente ativo (platina e paládio), que cristalizava e sinterizava durante a vida útil do catalisador, causando uma diminuição da atividade catalítica ${ }^{81}$.

A primeira geração dos catalisadores automotivos era constituída de platina, paládio (numa razão de 2,5:1 em peso) e cerca de $0,05 \%$ de metais preciosos totais suportados sobre $\gamma-\mathrm{Al}_{2} \mathrm{O}_{3}$ (contendo óxido de cério e de lantânio), depositada sobre um monólito de cordierita $\left(2 \mathrm{MgO} .2 \mathrm{Al}_{2} \mathrm{O}_{3} .5 \mathrm{SiO}_{2}\right)$ em forma de colméia ${ }^{11}$.

A segunda geração surgiu por volta de 1979, como conseqüência da restrição das exigências dos padrões de emissão de óxidos de nitrogênio, que não deveriam ultrapassar $0,6 \mathrm{~g} / \mathrm{Km}$. Neste caso, como a redução desses compostos é mais eficiente em misturas deficientes de oxigênio, ao contrário da oxidação do monóxido de carbono e hidrocarbonetos, propôs-se um conversor com dois leitos catalíticos, em que os óxidos de nitrogênio eram reduzidos por esses compostos, no primeiro leito, e estes últimos eram oxidados no segundo leito. Neste arranjo, o oxigênio era alimentado após o primeiro leito garantindo as condições de misturas ideais para os dois processos. Entretanto, o metal mais promissor para a redução (rutênio) apresentou baixa estabilidade térmica, nas condições de operação, o que inviabilizou o seu emprego comercial. Por outro lado, com a platina ou paládio os óxidos de nitrogênio seriam convertidos a amônia e não a nitrogênio. A amônia formada seria, então, convertida novamente a óxido de nitrogênio no segundo leito catalítico. Outra opção considerada foi o uso do ródio, um eficiente catalisador de redução, mas esse metal também levava à produção de amônia ${ }^{11,82}$.

A solução encontrada para esses problemas foi alcançada através da construção de um conversor em único estágio, que operava numa razão ar/combustível próxima à estequiométrica. Como mostra a Figura 3, existe uma faixa estreita dessa razão em que os três poluentes são convertidos simultaneamente, em quantidades apreciáveis. Para que essa tecnologia se tornasse factível, no entanto, era necessário manter essa razão na faixa considerada, durante todo o tempo de operação. Isto foi possível pelo desenvolvimento de um sensor de oxigênio, que foi posicionado antes do leito catalítico, no sistema de exaustão. Essa tecnologia foi chamada "catalisador de

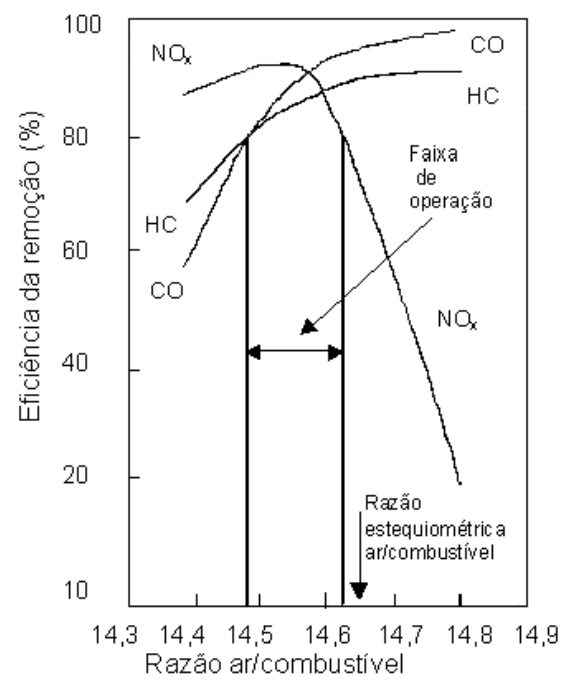

Figura 3. Diagrama da eficiência de remoção de monóxido de carbono, hidrocarbonetos e óxidos de nitrogênio, em função da razão ar/combustível ${ }^{11}$ três vias" (TWC, "Three Way Catalyst") e foi instalada nos primeiros veículos em 1979. Esses sistemas empregavam a platina e o ródio, este último sendo o maior responsável pela redução dos óxidos de nitrogênio ${ }^{11}$.

Entretanto, a natureza oscilatória da razão ar/combustível, no sistema de exaustão, levava a variações na composição da mistura gasosa, tornando-a alternadamente rica e deficiente em oxigênio. Isto gerou a necessidade do desenvolvimento de um componente que pudesse liberar ou absorver oxigênio durante as oscilações da razão ar/combustível ${ }^{83}$. Os testes conduzidos com óxido de cério $\left(\mathrm{CeO}_{2}\right)$ confirmaram a sua eficiência, devido às suas propriedades redox e, ainda hoje, ele é usado nos modernos catalisadores de três vias. As reações que ocorrem neste componente são mostradas pelas equações (36) e (37) 11 .

$\mathrm{CeO}_{2}+\mathrm{CO} \longrightarrow \mathrm{Ce}_{2} \mathrm{O}_{3}+\mathrm{CO}_{2}$ (deficiência de oxigênio)

$\mathrm{Ce}_{2} \mathrm{O}_{3}+1 / 2 \mathrm{O}_{2} \longrightarrow \mathrm{CeO}_{2}+\mathrm{CO}$ (excesso de oxigênio)

Outro benefício do óxido de cério é a sua capacidade de catalisar a reação com o monóxido de carbono e com os hidrocarbonetos, em condições de excesso de oxigênio, de acordo com as equações (38) e (39). O hidrogênio formado reduz os óxidos de nitrogênio, de acordo com a equação (40). Além dessas vantagens, o óxido de cério estabiliza a dispersão metálica ${ }^{84}$. Todavia, ele apresenta a desvantagem de interagir com a platina, durante sua vida útil ${ }^{85}$.

$\mathrm{CO}+\mathrm{H}_{2} \mathrm{O} \stackrel{\mathrm{CeO}_{2}}{\longrightarrow} \mathrm{CO}_{2}+\mathrm{H}_{2}$
$\mathrm{C}_{\mathrm{x}} \mathrm{H}_{\mathrm{y}}+2 \mathrm{H}_{2} \mathrm{O} \longrightarrow(2+\mathrm{y} / 2) \mathrm{H}_{2}+\mathrm{xCO}_{2}$
$\mathrm{NO}_{\mathrm{x}}+\mathrm{x} \mathrm{H}_{2} \longrightarrow \mathrm{N}_{2}+\mathrm{x} \mathrm{H}_{2} \mathrm{O}$

Outros sistemas óxidos, tais como $\mathrm{NiO} / \mathrm{Ni}$ e $\mathrm{Fe}_{2} \mathrm{O}_{3} / \mathrm{FeO}$, também têm sido usados como componentes de estocagem de oxigênio ${ }^{11}$. Os óxidos de manganês $\left(\mathrm{MnO}_{\mathrm{x}}\right)$ suportados em aluminatos também são promissores, apresentando diversas vantagens, como maior capacidade de estocar oxigênio numa faixa maior de temperatura, oxidar diretamente o metano e gerar monóxido de carbono e hidrogênio, sob condições oxidantes ${ }^{86}$. Recentemente, observou-se que os óxidos mistos do tipo $\mathrm{CeO}_{2}-\mathrm{ZrO}_{2}$ mostraram maior estabilidade térmica e capacidade de estocar oxigênio em comparação aos catalisadores de três vias tradicionais à base de óxido de cério ${ }^{87}$. Outro sistema $\left(\mathrm{PrO}_{\mathrm{y}}-\mathrm{CeO}_{2}\right)$ mostrou um desempenho superior àquele à base de óxido de zircônio ${ }^{88}$.

Os catalisadores de três vias, dessa geração, eram constituídos de cerca de 0,1 a $0,15 \%$ de metais nobres $(\mathrm{Pt} / \mathrm{Rh}=1-5)$, altas concentrações de óxido de cério com elevada área específica e alumina $(\gamma$ $\mathrm{Al}_{2} \mathrm{O}_{3}$ ) estabilizada com 1-2\% de óxido de lantânio e/ou óxido de bário, depositados num monólito de cordierita, em forma de colméia $^{89}$.

Por volta de 1980, houve necessidade de se melhorar a tecnologia dos catalisadores automotivos, diante dos novos desafios relacionados à economia de combustível e às novas velocidades de operação, que resultaram em temperaturas de exposição mais elevadas dos catalisadores e em atmosferas mais oxidantes. Isto causou a reação do ródio com a alumina, formando espécies ródio-aluminato inativas, levando à desativação do catalisador e ao desenvolvimento dos sistemas de terceira geração ${ }^{11}$.

Diversos estudos foram conduzidos com a finalidade de reduzir a reação do ródio com a alumina estabilizada. Observou-se que a reação de formação dos aluminatos, que ocorria a temperaturas superiores a $900{ }^{\circ} \mathrm{C}$, sob condições de deficiência de oxigênio, poderia ser revertida, em excesso de oxigênio, como mostram as equações (41) e (42). 


$$
\begin{array}{ll}
\mathrm{Rh}_{2} \mathrm{O}_{3}+\gamma-\mathrm{Al}_{2} \mathrm{O}_{3} \stackrel{800{ }^{\circ} \mathrm{C} \text {, deficiência de } \mathrm{O}_{2}}{\longrightarrow} \\
\mathrm{Rh}+\gamma-\mathrm{Al}_{2} \mathrm{O}_{3} & \mathrm{RhAl}_{2} \mathrm{O}_{3} \\
\mathrm{RhAl}_{2} \mathrm{O}_{3}+\mathrm{H}_{2}
\end{array}
$$

O catalisador essencialmente recupera sua atividade e o ciclo reversível sugere a formação de um complexo lábil do ródio. Todavia, o mecanismo de desativação desse catalisador é ainda objeto de controvérsias $^{87}$.

$\mathrm{O}$ ródio pode também interagir com o óxido de cério e com os óxidos de terras raras, reduzindo a atividade dessas espécies. Exposto a condições de altas temperaturas, e em excesso de oxigênio, ele pode reagir com o metal terra rara, reduzindo a atividade de ambos os metais. A suspeita de que a segregação do ródio poderia aumentar a sua resistência térmica resultou no desenvolvimento de catalisadores formados por diferentes camadas de ródio e óxido de cério. Outros estudos foram conduzidos com a finalidade de estabilizar o cério com óxidos de zircônio, bário e lantânio ${ }^{91}$.

A desativação do catalisador e o envenenamento por fósforo e enxôfre ainda são problemas que afetam os catalisadores modernos. O fósforo, oriundo do óleo lubrificante (como fosfato de tricresol), deposita-se sobre o catalisador, geralmente como um filme de $\mathrm{P}_{2} \mathrm{O}_{5}$ ou polimeriza na superfície da alumina; ambos os processos levam à desativação, pelo bloqueio dos poros do suporte, dificultando o acesso das moléculas reagentes aos sítios metálicos ativos ${ }^{92}$. Alguns estudos também apontaram o silício, proveniente de alguns óleos lubrificantes, como veneno desses sistemas ${ }^{8}$.

Os compostos de enxofre, presentes na gasolina (200-500 ppm) podem ser convertidos a óxidos de enxofre. O primeiro é adsorvido pelos metais nobres a temperaturas inferiores a $300{ }^{\circ} \mathrm{C}$, inibindo as conversões de monóxido de carbono, óxidos de nitrogênio e hidrocarbonetos. A temperaturas mais altas, o $\mathrm{SO}_{2}$ é convertido a $\mathrm{SO}_{3}$, que passa através do leito catalítico, ou pode reagir com a alumina para formar sulfato de alumínio, levando à desativação do catalisador. Além disso, o $\mathrm{SO}_{3}$ pode reagir com o cério e elementos das terras $\operatorname{raras}^{49}$.

Em 1990, foi mostrada uma evidência da aplicação do paládio como componente dos catalisadores automotivos e, em 1995, esse sistema foi comercializado pela Ford ${ }^{83}$. As condições de performance eram similares aos sistemas à base de platina graças a uma especial combinação de camadas de cério estabilizado e de alumina. $\mathrm{O}$ uso do paládio continua em expansão, especialmente em veículos com altas temperaturas de operação e baixas razões ar/combustível.

A quarta geração de catalisadores automotivos surgiu em meados de 1990, como resultado do custo inferior do paládio, quando comparado à platina, aliado à sua eficiência para remover hidrocarbonetos. Uma das principais modificações na tecnologia TWC tradicional foi a substituição da platina e/ou ródio pelo paládio, em certas aplicações comerciais, de modo a reduzir os custos desses sistemas. O desempenho do paládio é satisfatório em condições muito restritivas, mas com o aumento do custo do ródio, no final da década de oitenta, aumentou-se o interesse pela pesquisa de novos substitutos para esse metal. Paralelamente a essas pesquisas, ocorreram diversas mudanças nos motores dos veículos leves, aumentando as possibilidades de uso do paládio, em substituição ao ródio. Basicamente, os veículos foram projetados para operar numa estreita razão ar/combustível, com uma perturbação mínima dessa razão, resultando em melhores desempenhos. Ao mesmo tempo, a qualidade do combustível foi melhorada e o catalisador foi posicionado no sistema de exaustão de modo a sofrer um aquecimento mais rápido e alcançar temperaturas estacionárias mais elevadas, o que levou a uma redução do envenenamento do catalisador pelo fósforo e pelo enxofre $^{8}$.
O catalisador de três vias típico é constituído por um óxido refratário (especialmente alumina) e estabilizadores $\left(\mathrm{ZrO}_{2}, \mathrm{MgO}, \mathrm{CaO}\right.$, $\mathrm{SnO}, \mathrm{Y}_{2} \mathrm{O}_{3}, \mathrm{TiO}_{2}, \mathrm{ZnO}, \mathrm{B}_{2} \mathrm{O}_{3}, \mathrm{P}_{2} \mathrm{O}_{5}, \mathrm{SnO}_{2}, \mathrm{Bi}_{2} \mathrm{O}_{3}, \mathrm{SiO}_{2}$ ), podendo conter ou não promotores de óxidos alcalinos $\left(\mathrm{Li}_{2} \mathrm{O}, \mathrm{Na}_{2} \mathrm{O}, \mathrm{K}_{2} \mathrm{O}\right.$, $\mathrm{Cs}_{2} \mathrm{O}$ ) e sempre possuem pelo menos um metal nobre (Pt, Pd sozinhos ou associados a $\mathrm{Rh}$, Ir e/ou Rh). O ródio é o componente principal. A carga de metal nobre é de aproximadamente $1 \mathrm{~g} / \mathrm{l}$, com uma relação $\mathrm{Pt} / \mathrm{Rh} 10 / 1^{75}$. Dessa forma, o que distingue os vários catalisadores são os metais nobres presentes e os aditivos metálicos básicos como cobre, vanádio, cromo, ferro, cobalto, níquel ${ }^{1}$. Também eles se diferenciam pela maneira de preparação. Além dos metais nobres, o óxido de cério ou a mistura deste com o óxido de lantânio são adicionados para aumentar a estabilidade térmica da alumina e estabilizar a conversão em leves perturbações da razão ar/ combustível ${ }^{75}$.

\section{CONTROLE DA QUALIDADE DO AR ATRAVÉS DOS CATALISADORES AUTOMOTIVOS}

A poluição do ar é principalmente um problema em áreas urbanas e muito industrializadas, onde o fluxo de ar puro das áreas vizinhas é insuficiente para dispersar os poluentes. Os motores veiculares são responsáveis por mais de $50 \%$ das emissões antropogênicas de monóxido de carbono, hidrocarbonetos e óxidos de nitrogênio. As fontes naturais emitem muito mais poluentes que as antropogênicas, mas os poluentes são amplamente dispersos e não contribuem grandemente para os problemas de poluição urbana ${ }^{82}$.

A abundância de automóveis e de luz solar na Califórnia deu origem a sérios problemas ambientais, tornando este Estado o pioneiro no controle das emissões automotivas, desde 1960. A primeira lei federal que afetou o projeto dos automóveis foi promulgada em 1970, exigindo uma redução de $90 \%$ de monóxido de carbono e hidrocarbonetos, seguida de uma outra que estabelecia a mesma exigência para os óxidos de nitrogênio. Recentemente, a legislação restringiu as emissões máximas de hidrocarbonetos para $0,077 \mathrm{~g} . \mathrm{Km}^{-1}$ (comparados a 0,25 g. Km ${ }^{-1}$ em 1991), de monóxido de carbono para 1,0 g. $\mathrm{Km}^{-1}$ (2,1 g. $\mathrm{Km}^{-1}$ em 1991) e de óxidos de nitrogênio para $0,12 \mathrm{~g} \cdot \mathrm{Km}^{-1}\left(0,61 \mathrm{~g} \cdot \mathrm{Km}^{-1} \mathrm{em} \mathrm{1991)}\right.$ a serem atingidas até $2004^{8,82}$.

Neste contexto, os catalisadores automotivos têm se apresentado como a melhor alternativa e, ao longo do tempo, têm respondido aos constantes desafios impostos por legislações cada vez mais restritivas. A Tabela 3 ilustra o papel dos catalisadores na redução dos poluentes, no período de 1970 a 1985 , em que se verificou os progressos mais significativos no controle das emissões automotivas ${ }^{2}$.

Tabela 3. Redução de emissão de poluentes resultante do uso de catalisadores automotivos ${ }^{2}$

\begin{tabular}{lcccc}
\hline \multirow{2}{*}{$\begin{array}{l}\text { Poluente } \\
\left.\text { g } . \mathrm{Km}^{-1}\right)\end{array}$} & 1970 & 1975 & 1980 & 1985 \\
\hline Monóxido de carbono & 20 & 9 & 5 & 1,8 \\
Hidrocarbonetos & 2 & 1 & 0,6 & 0,6 \\
Óxidos de nitrogênio & $\begin{array}{c}\text { (não havia } \\
\text { controle) }\end{array}$ & 1,9 & 1,2 & 0,67 \\
& & & \\
\hline
\end{tabular}

No Brasil, os esforços para controlar a qualidade do ar começaram em 1976, quando foram estabelecidos padrões nacionais e federais para o monóxido de carbono, o dióxido de enxofre, as partículas em suspensão e os oxidantes fotoquímicos. Entretanto, apenas em 1986 foram promulgadas leis, através da CETESB e do IBAMA, visando o controle da qualidade do ar, sendo criado um programa 
(PROCONVE- Programa de Controle da Poluição do Ar por Veículos Automotores) que estabelecia limites de emissões para o monóxido de carbono, os hidrocarbonetos e os óxidos de nitrogênio.

Por outro lado, a implementação do PROALCOOL, há vinte anos, contribuiu de modo significativo para alterar as características da atmosfera brasileira, ao estabelecer o uso de etanol hidratado ou uma mistura de $24 \%$ de etanol anidro e gasolina como combustível. Neste caso, as emissões de dióxido de enxofre, de compostos aromáticos, de olefinas e de fuligem são reduzidas, enquanto a produção de aldeídos e monóxido de carbono é aumentada ${ }^{82}$. Esses compostos são danosos à saúde humana, além de participarem de reações atmosféricas na formação do ozônio e da chuva ácida.

Atualmente, a frota brasileira é altamente diversificada, com veículos leves e pesados, movidos a álcool, gasolina-álcool ou óleo diesel, gerando complexos problemas de poluição. Em particular, a concentração de acetaldeído é muito elevada, quando comparada a outras cidades do mundo. Isto gerou a necessidade do estudo da eliminação dos compostos oxigenados e diversos trabalhos foram conduzidos, visando ao desenvolvimentos de catalisadores mais adequados à essa atmosfera ${ }^{38}$.

Os limites máximos de emissão desses poluentes, para motores e veículos novos, é estabelecido pelo PROCONVE, que também regulamenta o licenciamento para fabricação do veículo ou motor e para a verificação da conformidade da produção. O órgão foi baseado na experiência internacional de países desenvolvidos que exigem que veículos e motores atendam a limites máximos de emissão em ensaios padronizados e com combustíveis de referência. O programa impõe a certificação de protótipos e verificações de veículos de linha de produção e autorização do órgão ambiental federal para o uso de combustíveis alternativos. Além disto, prevê o recolhimento e reparo de veículos ou motores em desacordo com a produção ou o projeto, proibindo também a comercialização de veículos não homologados segundo seus critérios. Os fabricantes vêm cumprindo satisfatoriamente as exigências legais, o que permitiu a redução média da ordem de $80 \%$ na emissão de poluentes nos veículos. Uma redução mais significativa se dará somente a partir da implantação do I/MPrograma de Inspeção e Manutenção de Veículos e Motores, que fiscalizará a frota das grandes cidades e emitirá pareceres que poderão liberar ou reprovar os veículos em circulação, em função das suas condições.

A qualidade do combustível é também um importante aspecto a ser considerado no controle da qualidade do ar. Neste aspecto, a PETROBRÁS tem como meta reduzir os teores de enxofre, compostos aromáticos, MTBE e olefinas leves, tanto na gasolina como no óleo diesel.

A implementação pioneira dos catalisadores automotivos nos EUA, causada pelas legislações governamentais, os benefícios resultantes na qualidade do ar e a relativa simplicidade, aliados à economia de combustível, tornou esses sistemas a mais nova e recente aplicação dos catalisadores. O impacto do uso desses materiais pode ser avaliado pelo fato deles terem padronizado alguns aspectos dos projetos dos automóveis em países como EUA e Japão, que logo se estenderam a outros países. Estima-se que nos próximos dez anos, esses catalisadores deverão continuar como um componente essencial dos automóveis ${ }^{49}$.

O estágio avançado de desenvolvimento da oxidação do monóxido de carbono pode ser atribuído a: (i) os inúmeros estudos fundamentais que foram conduzidos ao longo dos anos, definindo o mecanismo das reações e as características dos catalisadores e (ii) o impulso resultante do esforço conjunto de diversas companhias automobilísticas, nos últimos anos. O segundo ponto evitou o desenvolvimento de catalisadores restritos a um dado tipo de automóvel, além de promover o desenvolvimento de novos conceitos na ciência da catálise, aplicados ao desenvolvimento global do sistema catalítico veicular.

\section{TECNOLOGIAS EMERGENTES E OS NOVOS DESAFIOS}

Os requisitos pelo ar cada vez mais limpo continuam a demandar catalisadores mais eficientes. Com a atual geração dos catalisadores de três vias, a maioria das emissões dos hidrocarbonetos (60-80\% do total emitido) é produzida na parte mais fria do motor, nos primeiros dois minutos de operação. Como as exigências no controle ambiental tornam-se cada vez mais rigorosas, deve continuar a haver esforços para reduzir ainda mais a quantidade desses hidrocarbonetos. Dessa forma, diversos estudos têm enfocado o aumento da velocidade de destruição desses poluentes, nos primeiros dois minutos de operação, através das seguintes estratégias: (i) sistema duplo de catalisador seguido de um outro; (ii) dispositivo para reter os hidrocarbonetos e (iii) monólito metálico aquecido ${ }^{8}$.

Considerando as restrições econômicas dos sistemas automotivos de abatimento de poluentes, não é provável que se encontre novas composições de catalisadores que sejam suficientemente ativas e que possam ser posicionadas de modo a vencer o desafio de eliminar as emissões de hidrocarbonetos. Uma alternativa viável é montar um catalisador menor próximo à câmara de combustão, de modo que a temperatura, necessária para que as reações catalíticas sejam iniciadas, possa ser alcançada mais rapidamente. Existe ainda o interesse pela pesquisa de novos suportes que possam apresentar elevadas áreas superficiais e combinações de metais que possam resistir à desativação, devido à sinterização pela exposição a altas temperaturas.

Uma alternativa promissora é promover a adsorção dos hidrocarbonetos até que o catalisador atinja a temperatura em que as reações catalíticas são iniciadas e, posteriormente, promover a sua dessorção, de modo que eles possam ser oxidados durante o ciclo catalítico.

Outro aspecto a ser considerado, nas novas tecnologias, é o potencial de formação do ozônio e a reatividade dos compostos orgânicos emitidos. A formação do ozônio pode ser controlada através de catalisadores ou de mudanças no tipo ou composição do combustível $^{8}$.

A redução dos óxidos de nitrogênio em ambientes com excesso de oxigênio é uma outra tecnologia cuja investigação tende a crescer. Essa estratégia de operação também diminui as emissões de dióxido de carbono, causador do efeito estufa. Quando há excesso de oxigênio, a redução de óxidos de nitrogênio é inibida e, portanto, novos catalisadores devem ser desenvolvidos. Esse sistema deve ser integrado ao motor, de modo que o vapor, na exaustão, possua o tipo e a quantidade de hidrocarbonetos necessários para reduzir esses óxidos a uma temperatura ótima para um hidrocarboneto particular. Apesar de intenso trabalho ter sido desenvolvido nessa área, durante a década passada, uma tecnologia viável ainda não foi desenvolvida. A principal preocupação é a durabilidade do catalisador no sistema de exaustão. Essa área certamente continuará a receber muita atenção ${ }^{93}$.

Os combustíveis alternativos são outra área de estudo. Gás natural e álcoois são substitutos promissores para a gasolina, pelo fato de serem potencialmente menos poluentes ${ }^{33}$. Os combustíveis sintéticos contendo nitrogênio são particularmente atrativos, mas podem gerar quantidade elevadas de óxidos de nitrogênio, sobre catalisadores à base de metais nobres ${ }^{7}$. Nestes casos, novos catalisadores precisam ser desenvolvidos.

Finalmente, a modelagem e o aumento de escala dos catalisadores automotivos exige o entendimento da cinética das reações heterogênea e homogênea e do possível papel desempenhado pelas espécies superficiais formadas, em iniciar e promover as reações homogêneas. 
Entretanto, muito poucas informações estão disponíveis na literatura. Além disso, embora tenham sido observados múltiplos estágios estacionários nos combustores catalíticos, nenhum modelo está de fato disponível para predizê-lo satisfatoriamente. Esse modelo seria importante para prever a estabilidade de operação desses sistemas.

Para os cientistas e engenheiros atuantes na área de catalisadores automotivos, o desafio atual é produzir catalisadores que possam ser utilizados, sem nenhuma restrição para o meio ambiente, e produzir conversores que possam proteger adequadamente os catalisadores. Isto garantirá que os catalisadores continuem a representar uma solução a longo prazo no controle das emissões automotivas.

\section{CONCLUSÕES}

As nações civilizadas têm sofrido severos problemas de poluição, nos últimos quarenta anos, gerando medidas legislativas, cada vez mais restritivas, com a finalidade de garantir a qualidade do ar. Nos centros urbanos, os automóveis são os principais poluidores, através da emissão de monóxido de carbono, hidrocarbonetos e óxidos de nitrogênio, causadores de sérios danos à saúde humana.

Ao longo dos anos, as leis ambientais tornaram-se cada vez mais restritivas, o que levou ao desenvolvimento de novas tecnologias e à melhoria da qualidade dos combustíveis. Essas restrições tendem a aumentar cada vez mais, como consequiência da maior conscientização da população e dos organismos governamentais pela necessidade de um ar mais limpo.

Neste contexto, os catalisadores, aliados a alterações nos projetos dos automóveis, atenderam de modo eficiente aos constantes desafios e são, atualmente, considerados como um componente indispensável dos automóveis. Nos dias atuais, os catalisadores de três vias representam a tecnologia mais competitiva para alcançar os padrões exigidos para a qualidade do ar.

Todavia, existem várias dificuldades associadas ao desenvolvimento dos catalisadores automotivos, tais como reproduzir os sistemas reais no laboratório, uma vez que diversas reações podem ocorrer simultanemente. Além disso, esses sistemas apresentam características distintas daqueles usados em processos industriais ${ }^{75}$. No último caso, as condições para o melhor desempenho do catalisador podem ser ajustadas (pressão, temperatura, concentração) enquanto, no controle ambiental, o catalisador deve ser adaptado às condições do gás efluente a ser tratado. Quando a aplicação desse estudo é no sistema de exaustão do automóvel, então a complexidade é notória, pois os compostos emitidos dependem de diversos fatores como o tipo do combustível, dos seus aditivos, da temperatura da queima e da relação ar/combustível, entre outros.

Existem inúmeros estudos sobre as propriedades e a utilização de catalisadores automotivos para veículos movidos à gasolina. Apesar disso, há um consenso geral sobre a necessidade de se desenvolver sistemas mais eficientes, que possam operar a temperaturas superiores a $1173 \mathrm{~K}$, numa faixa da razão ar/combustível mais ampla e que contenham menor quantidade de metais nobres. A exposição térmica do catalisador de três vias pode levar à sinterização dos metais nobres e à diminuição da área superficial específica do suporte 9 . No caso de veículos movidos a álcool ou a álcool-gasolina, existe o problema adicional do controle das emissões de álcoois, aldeídos e ácidos carboxílicos ${ }^{40}$.

Assim sendo, esta área recebeu, nos últimos trinta anos, bastante atenção por parte da comunidade científica e continua aberta à investigação de novos materiais que venham atender às condições de redução dos metais nobres (menos disponíveis), redução na deterioração do catalisador (muito sensível a venenos, como compostos de enxofre, presentes na maioria dos combustíveis) e alta eficiência com misturas gasolina/etanol e com os aditivos presentes.

\section{REFERÊNCIAS}

1. Briggs, W.S. Em Applied Industrial Catalysis; Leach, B. E., ed.; Academic Press: Orlando, 1984.

2. Acres, G. J. K. Em Perspective in Catalysis; Thomas, J. M.; Zamaraev, K. I., eds.; Blackwell Scientific Publications; Oxford, 1992, p. 242.

3. Miguel, A. H.; Andrade, J. B. de; J. Braz. Chem. Soc. 1990, $1,124$.

4. Tanner, R. L.; Miguel, A. H.; Andrade, J. B. de; Gaffney, J. S.; Streit, E.; Environ. Sci. Technol. 1988, 22, 1026.

5. Botkin, D.; Keller, E.; Environmental Science-Earth as Living Planet, John Willey and Sons: New York, 1995.

6. Mazzarino, I.; Barresi, A. A.; Catal. Today 1993, 17, 335.

7. Prasad, R.; Kennedy, L. A.; Ruckenstein, E.; Catal. Rev. 1984, $26,1$.

8. Dwyer, F. G.; Catal. Rev. 1972, 6, 261.

9. Taylor, C. K. Em Catalysis. Science and Technology; Anderson, J. R.; Boudart, M., eds.; Springer-Verlog: Berlin, 1984.

10. Kummer, J. Em Catalysts for the Control of Automotive Pollutants; McEvoy, J., eds.; American Chemical Society: Washington, D.C., 1975.

11. Heck, R. M.; Farrauto, R. J.; Catalytic Air Pollution Control, Van Nostrand Reinhold: New York, 1995.

12. Rijkeboer, R. C.; Catal. Today 1991, 11, 141.

13. Gainer, W. E.; Gray, T. J.; Stone, F. S.; Disc. Faraday Soc. 1950, 8, 246.

14. Pierron, E. D.; Rashkin, J. A.; Roth, J. P.; J. Catal. 1967, 9, 38.

15. Smith, A. W.; J. Catal. 1965, 9, 172.

16. Chon, H.; Prater, C. D.; Disc. Faraday Soc. 1966, 41, 380.

17. Hughes, M. F.; Hill, G. R.; J. Phys. Chem. 1955, 59, 388.

18. Shelef, M.; Otto, K.; Gandhi, H.; J. Catal. 1968, 12, 361.

19. Bond, G. C.; Catalysis by Metals, Academic Press: New York, 1962.

20. Kapteijn, F.; Stegenga, N. J. J.; Bijsterbosch, J. W.; Moulijn, J. A.; Catal. Today 1993, 16, 273.

21. Satterfield, C. N.; Heterogeneous Catalysis in Practice, Mc-Graw-Hill Book Company: New York, 1980.

22. Tulenin, Y. P.; Sinev, M. Y.; Savkin, V. V.; Korchak, V. N. Em Studies in Surface Science and Catalysis 110; Grasselli, R. K.; Oyama, S. T.; Gaffney, A. M.; Lyons, J. E., eds.; Elsevier: Amsterdam, 1997.

23. Ahuja, O. P.; Marthur, G. P.; Can. J. Chem. Eng. 1967, 43, 367.

24. Hiam, L.; Wise, H.; Chaikin, S.; J. Catal. 1963, 9, 272.

25. Dmuchovsky, B.; Freerks, M. C.; Zienty, F. B.; J. Catal. 1965, 4, 577.

26. Morooka, Y.; Ozaki, A.; J. Catal. 1966, 5, 116.

27. Sachtler, W. M. A.; de Boer, N. H.; Int. Congr. Catal., Elsevier: Amsterdam, 1964.

28. Cant, N. W.; Hall, W. K.; J. Catal. 1970, 16, 220.

29. Barnard, J. A.; Mitchell; J. Catal. 1968, 12, 386.

30. Garetto, T. F.; Apesteguia, C. R. Em Studies in Surface Science and Catalysis 130; Corma, A.; Melo, F. V.; Mendioroz, S.; Fierro, J. L. G., eds.; Elsevier: Amsterdam, 2000.

31. McCabe, R. W.; Mitchell, P. J.; Appl. Catal. 1986, 83, 27.

32. McCabe, R. W.; Mitchell, P. J.; J. Catal. 1987, 103, 419.

33. McCabe, R. W.; Mitchell, P. J.; Appl. Catal. 1988, 44, 73.

34. Vannice, M. A.; Mao, C.F.; J. Catal. 1995, 154, 230.

35. Srihari, V.; Viswanath, D. S.; J. Catal. 1976, 43, 45.

36. Ismagilov, Z. R.; Dobrynkin, N. M.; Popovskii, V. V.; React. Kinet. Catal. Lett. 1979, 10, 55.

37. Rajesh, H.; Ozkan, U.S.; Ind. Eng. Chem. Res. 1993, 32, 1622.

38. McCabe, R. W.; Mitchell, P. J.; Ind. Eng. Chem. Prod. Res. Dev. 1984, 23, 196.

39. Yao, Y. Y.; Ind. Eng. Chem. Prod. Res. Dev. 1984, 23, 60.

40. McCabe, R. W.; Mitchell, P. J.; Ind. Eng. Chem. Prod. Res. Dev. 1983, 22, 212.

41. Cheng, W. J.; Catal. 1996, 158, 477.

42. Miyadera, T.; Appl. Catal., B 1997, 13, 157.

43. Urizo, Y.; Miyadera, T.; Yoshida, A. A. K.; Catal. Lett. 1996, 37, 265.

44. Zhang, Y.; Flytzani, M. S. Em Environmental Catalysis; Arnor, J. N, ed.; American Chemical Society: Washington, D.C., 1993.

45. Kikutani, Y.; J. Mol. Catal. A: Chem. 1999, 142, 247.

46. Kikutani, Y.; J. Mol. Catal. A: Chem. 1999, 33, 265.

47. Spivey, J. J.; Butt, J. B.; Catal. Today 1992, 11, 465.

48. Hermia. J; Vigneron, S.; Catal. Today 1993, 17, 349.

49. Hightower, J. W. Em Studies in Surface Science and Catalysis. Preparation of Catalysis III; Poncelet, G.; Grange, P.; Jacobs, P. A., eds.; Elsevier: Amsterdam, 1983.

50. Marécot. P.; Fakche, A.; Kellali, B.; Mabilon, G.; Prigent, M.; Barbier, J.; Appl. Catal., B 1994, 3, 283.

51. Hijos, L. J.; Praliaud, H.; Primet, M.; Appl. Catal. 1993, 98, 125.

52. Briot, P.; Primet, M.; Appl. Catal. 1991, 68, 301.

53. Garbowski, E.; Feumi-Jantou, C.; Mouaddib, N.; Primet, M.; Appl. Catal., A 1994, 109, 277. 
54. Skoglundh, M.; Löwendahl, L. O.; Ottersted, J. E.; Appl. Catal. 1991, 77, 9.

55. Johnson, D.W.; J. Catal. 1977, 48, 87.

56. Wang, D.; Appl. Catal., A 1994, 112, 22.

57. Praserthdam, P.; Majitnapakul, T.; Appl. Catal., A 1994, 108, 21.

58. Vassileva, M.; Morez, E.; Dacheva, S.; Ushakov, V.; Andreev, A.; Appl. Catal., A 1994, 112, 141.

59. Micheaud, C.; Marécot, P.; Guérin, M.; Barbier, J.; Appl. Catal., A 1998, 171,229

60. Bozo, C.; Garbowski, E.; Guilhaume, N.; Primet, M. Em Studies in Surface Science and Catalysis 130; Corma, A.; Melo, F. V.; Mendioroz, S.; Fierro, J. L. G., eds.; Elsevier: Amsterdam, 2000.

61. Lahouse, C.; Cellier, C.; Delmon, B.; Grange, P. Em Studies in Surface Science and Catalysis 130; Corma, A.; Melo, F. V.; Mendioroz, S.; Fierro, J. L. G., eds.; Elsevier: Amsterdam, 2000.

62. Bosf, H.; Jansen, F.; Catal. Today, 1988, 2, 369.

63. Trimm, D.L.; Appl. Catal. 1983, 7, 249.

64. Boccuzi, F.; Guglielminotti, E.; Martra, G.; Cerrato, G.; J. Catal. 1994, $146,449$.

65. Yamaguchi, A.; Shido, T.; Asakura, K.; Iwasawa, Y. Em Studies in Surface Science and Catalysis 130; Corma, A.; Melo, F. V.; Mendioroz, S.; Fierro, J. L. G., eds.; Elsevier: Amsterdam, 2000.

66. Férnandez-García, M.; Martínez-Arias, A.; Anderson, J.A.; Conesa, J, C.; Soria, J. Em Studies in Surface Science and Catalysis 130; Corma, A.; Melo, F. V.; Mendioroz, S.; Fierro, J. L. G., eds.; Elsevier: Amsterdam, 2000.

67. Klimisch, R.L.; Barnes, G. J.; Environ. Sci. Technol. 1972, 6, 543.

68. Burch, R.; Urbano, F. J.; Appl. Catal., A 1995, 124, 121.

69. Bamwenda, G. R.; Ogata, A.; Obachu, A.; Oi, J.; Mizuno, K.; Skrzypeck, K.; Appl. Catal. 1995, 6, 344.

70. Yezerets, A.; Zheng, Y.; Park, P. W.; Kung, M. C.; Kung, H. H. Em Studies in Surface Science and Catalysis 130; Corma, A.; Melo, F. V.; Mendioroz, S.; Fierro, J. L. G., eds.; Elsevier: Amsterdam, 2000.

71. Chafik, T.; Kameoka, S.; Ukisu, Y.; Miyadera, T. Em Studies in Surface Science and Catalysis 130; Corma, A.; Melo, F. V.; Mendioroz, S.; Fierro, J. L. G., eds.; Elsevier: Amsterdam, 2000.

72. Cahmbers, D. C.; Angove, D. E.; Cant, N. W. Em Studies in Surface Science and Catalysis 130; Corma, A.; Melo, F. V.; Mendioroz, S.; Fierro, J. L. G., eds.; Elsevier: Amsterdam, 2000.
73. Achneider, S.; Rindler, S.; Girard, P.; Maire, G.; Garin. F.; Bazin, D. Em Studies in Surface Science and Catalysis 130; Corma, A.; Melo, F. V.; Mendioroz, S.; Fierro, J. L. G., eds.; Elsevier: Amsterdam, 2000.

74. Mello, L. F.; Baldanza, M. A. S.; Noronha, F. B.; Schmal, M. Em Studies in Surface Science and Catalysis 130; Corma, A.; Melo, F. V.; Mendioroz, S.; Fierro, J. L. G., eds.; Elsevier: Amsterdam, 2000.

75. Nakajima, F., Catal. Today, 1991, 10, 1.

76. Spassova, I.; Khristova, M.; Nyagolova, N.; Mehandjiev, D. Em Studies in Surface Science and Catalysis 130; Corma, A.; Melo, F. V.; Mendioroz, S.; Fierro, J. L. G., eds.; Elsevier: Amsterdam, 2000.

77. Gervasini, A.; Auroux, A. Em Studies in Surface Science and Catalysis 130; Corma, A.; Melo, F. V.; Mendioroz, S.; Fierro, J. L. G., eds.; Elsevier: Amsterdam, 2000.

78. Farrauto, R.; J. Catal. 1974, 33, 349.

79. Fisher, N.; Lee, R.; Environ. Sci. Technol. 1974, 8, 260.

80. Doelp, L.; Koester, D.; Mitchell, M.; Oxidative Automotive Emission Control Catalysis-Selected Factors Affecting Catalyst Activity, American Chemical Society: Washington, D.C., 1975.

81. Beguin, B.; Garbowski, E.; Primet, M.; J. Catal. 1991, 127, 595.

82. Wei, J.; Adv. Catal. 1975, 24, 57.

83. Harrison, B.; Diwell, A.; Hallet, C.; Plat. Met. Rev. 1988, 32, 73.

84. Golunski, S. E.; Hatcher, H. A.; Rajaram, R. R.; Truex, T. J.; Appl. Catal., B 1995, 5, 367 .

85. Nunan, J.G.; Robota, H. J.; Cohn, M. J.; Bradley, S.A. Em Studies in Surface Science and Catalysis 71; Crucq, A., ed.; Elsevier: Amsterdam, 1991.

86. Chang, Y.; McCarty, J. G.; Catal. Today 1996, 30, 163.

87. Fornasiero, P.; Di Monte, R.; Montini, T.; Kaspar, J.; Graziani, M. Em Studies in Surface Science and Catalysis 130; Corma, A.; Melo, F. V.; Mendioroz, S.; Fierro, J. L. G., eds.; Elsevier: Amsterdam, 2000.

88. Shigapov, A. N.; Jen, H. W.; Graham, G. W.; Chun, W.; McCabe, R. W. Em Studies in Surface Science and Catalysis 130; Corma, A.; Melo, F. V.; Mendioroz, S.; Fierro, J. L. G., eds.; Elsevier; Amsterdam, 2000.

89. Degobert, P.; Rev. Inst. Fr. Pet. 1985, 40, 635.

90. Wong, C.; McCabe, R.; J. Catal. 1989, 119, 47.

91. Williamson, W.; Perry, J.; Gandhi, H.; Bamback, J.; Appl. Catal. 1985, 15, 277.

92. Gandhi, H.; Shelef, M.; Appl. Catal. 1991, 77, 175.

93. Iwamoto, M.; Hamada, H.; Catal. Today 1991, 10, 57. 